\title{
$\mathrm{UiO}$ : Faculty of Law \\ University of Oslo
}

\section{The Right Not to be Subject to Automated Decisions Based on Profiling}

Applied to examples of online scoring technology, weblining, and behavioral advertising

Candidate number: 225

Submission deadline: 01.06.2016

Number of words: 32142 


\section{Table of contents}

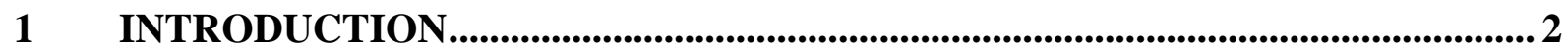

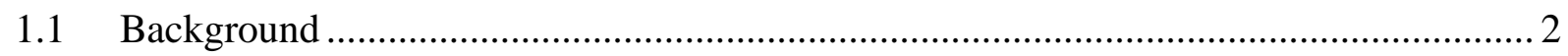

1.2 The questions to be addressed and the structure of the thesis ..................................... 3

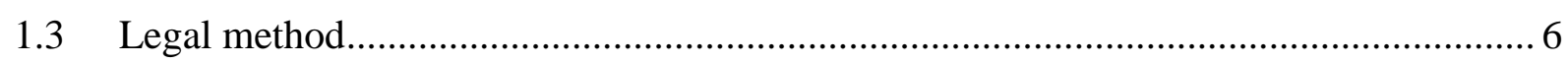

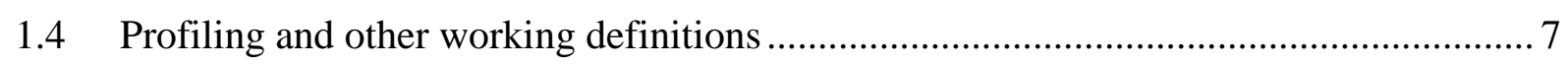

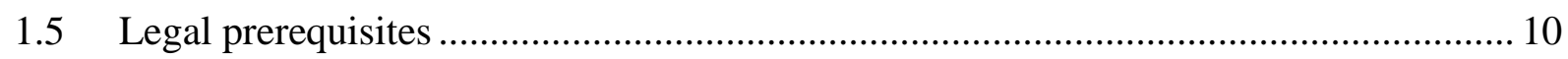

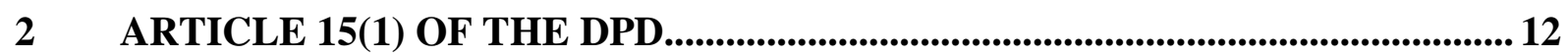

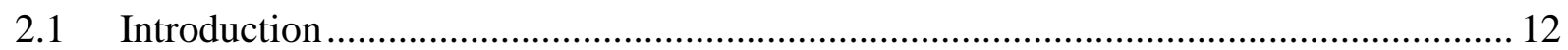

2.2 The content of the right: human re-examination...................................................... 14

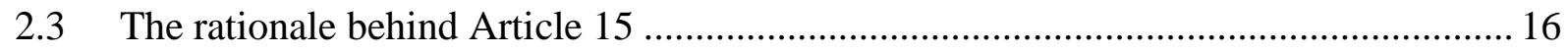

2.4 Condition 1: Profiling as a basis for decision-making ............................................. 20

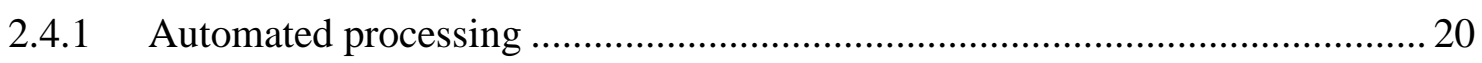

2.4.2 Intention to evaluate certain personal aspects ........................................... 21

2.5 Condition 2: A decision based on profiling ............................................................. 25

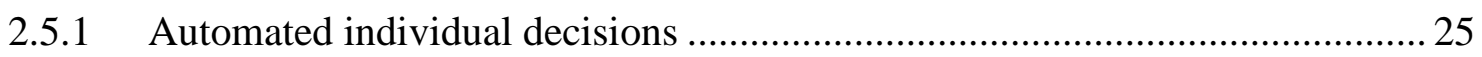

2.5.2 How the criterion of 'solely' should not be interpreted.................................. 27

2.5.3 The limits of human involvement in decision-making ................................. 28

2.6 Condition 3: The decision must be significant or cause legal effects ........................... 30

2.6.1 Alternative 1: Decisions producing legal effects.......................................... 30

2.6.2 Alternative 2: Decisions significantly affecting a person............................... 31

2.7 The subject of Article 15 and the entity accountable................................................. 33

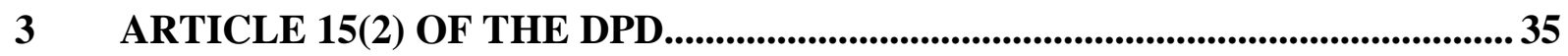

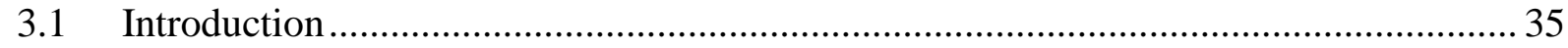

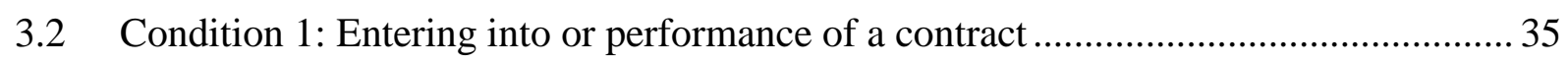

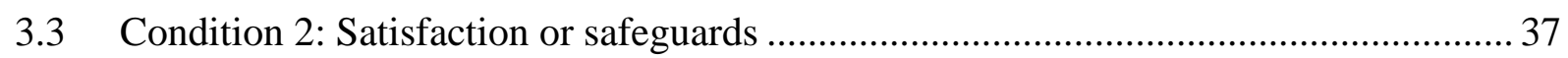

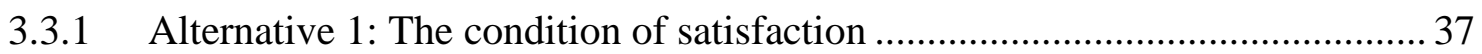

3.3.2 Alternative 2: The condition of safeguards .................................................... 38

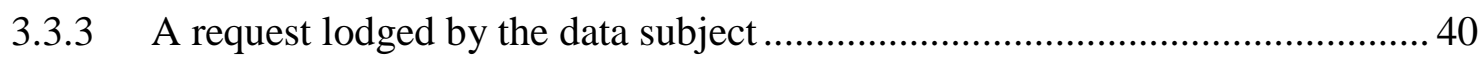

4 THE PRACTICAL APPLICATION OF ARTICLE 15......................................... 42

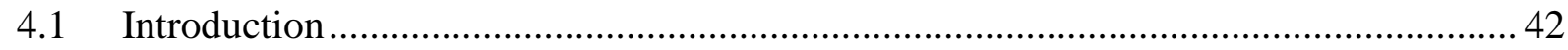

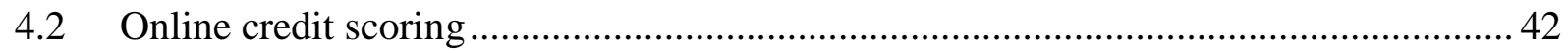

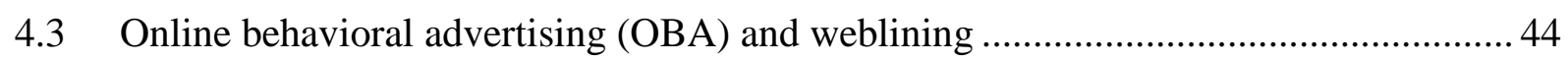

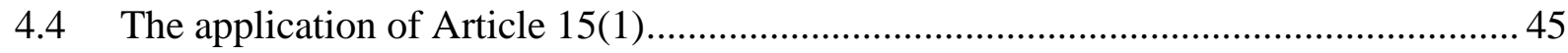




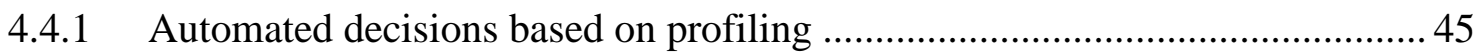

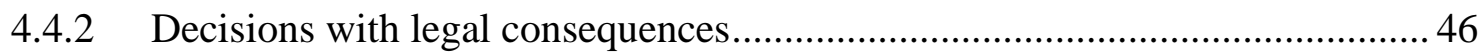

4.4.3 Decisions with significant consequences ............................................... 47

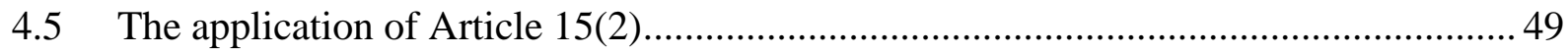

5 SECTION 25 OF THE NORWEGIAN PERSONAL DATA ACT ......................51

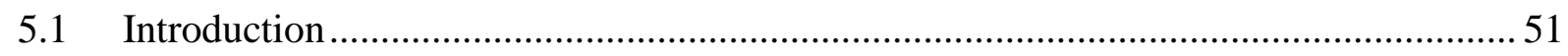

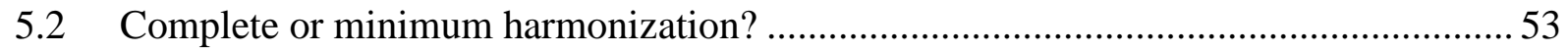

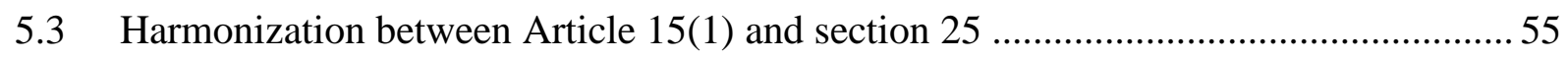

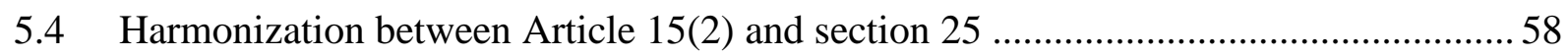

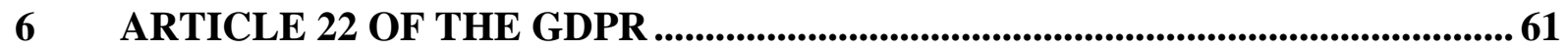

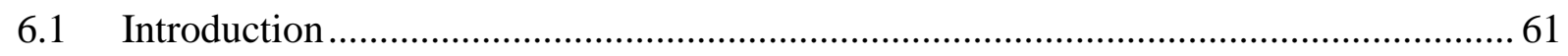

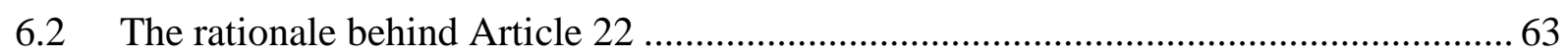

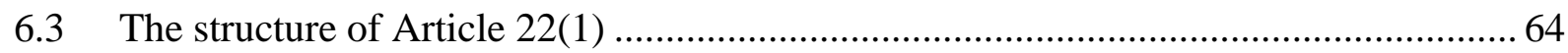

6.3.1 Change of condition 1? Profiling as a basis for decision-making .................... 64

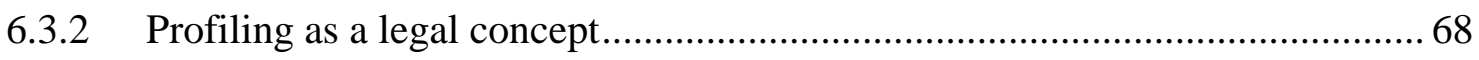

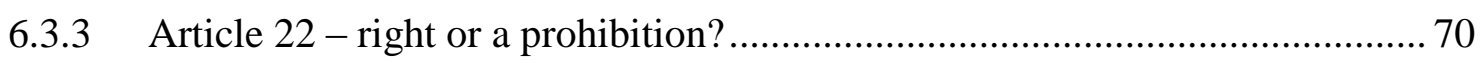

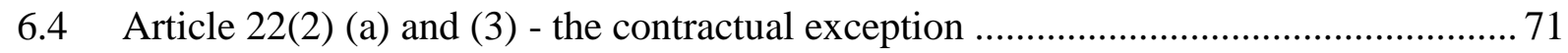

6.4.1 Condition 1: entering into or performance of a contract ................................ 71

6.4.2 Condition 2: safeguards and the right of human intervention .......................... 73

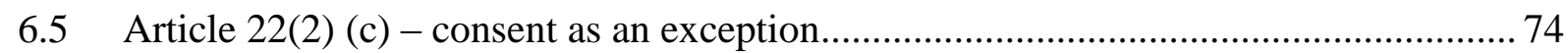

6.6 Article 22(4) - the prohibition of decisions based on sensitive data ............................ 76

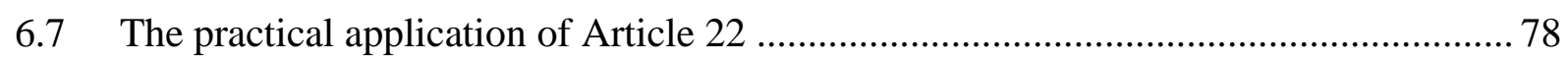

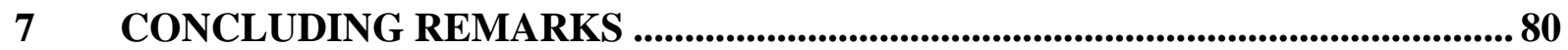

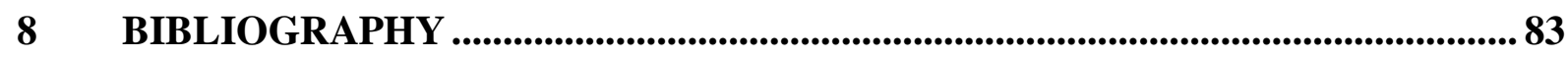




\section{Abbreviations}

CJEU

DPD

EEA Agreement

EFTA

GDPR

OBA

TEU

TFEU
Court of Justice of the European Union

EU Data Protection Directive 95/46 EC

Agreement on the European Economic Area

European Free Trade Association

General Data Protection Regulation EU 2016/679

Online behavioral advertising

Treaty on the European Union

Treaty on the Functioning of the European Union 


\section{Introduction}

\subsection{Background}

This thesis examines the right not to be subjected to automated decisions based on profiling, as governed by EU law. Decisions are automated if they are solely made by a computer. Profiling is as a working definition in this thesis, defined as an evaluation of certain personal aspects relating to a person, which can include the behavior and characteristics of that person. ${ }^{1}$ Thus, profiling is seen as an automated process, which can end up in a profile. ${ }^{2}$

For over twenty years Article 15 of the EU Data Protection Directive ${ }^{3}$ (DPD) has regulated automated decisions and profiling. Article 15 grants, in summary, every person a qualified right not to be subject to automated decisions based on profiling, if it has legal or significant consequences for the person.

European citizens are increasingly subject to such decisions, for instance in the approval of consumer loans, the granting of credit in online shops, and also in the customization of offers and advertisement on the Internet. The same way industrial machines replaced manual labor, computers are now completing tasks formerly done by intellectual means. It is no longer necessary to have a person evaluate the creditworthiness of a borrower, when an algorithm can do this assessment much more efficiently and possibly more accurately.

Sometimes these automated decisions are based on profiling of the person subjected to the decision. Information about individuals and their behavior can increase the accuracy of the decisions. In other words, persons reading sports news will have a higher chance of receiving offers on sporting equipment. Subsequently, profiling has to some extent become the source of revenue for several information services, like online newspapers, social media, and online shops. ${ }^{4}$ The more an online newspaper can provide customized ads on their website the higher the click rate of those ads become. ${ }^{5}$

However, combining automated decision making and profiling has not only made some services more efficient; it also poses dangers to privacy and data protection. In 2002, the American company Target made statistical models for the purpose of predicting which of their fe-

1 This definition is taken from Article 15(1) DPD and Article 4(4) GDPR

2 I return to the concept of automated processing in subsection 1.4.

3 Directive 95/46/EC of the European Parliament and of the Council of 24 October 1995 on the protection of individuals with regard to the processing of personal data and on the free movement of such data.

$4 \quad$ Datatilsynet (2015) p. 23 and 28.

5 Oxford Dictionaries (2016). Click rate is a term used for how often a person visits a web site through a hypertext link to the site. 
male customers were in their third trimester of pregnancy. ${ }^{6}$ Consequently, Target could target these customers with offers of diapers. Another example of computerized profiling is how several e-commerce sites individualize their pricing. Research shows that users of Macintosh computers and Android devices on average risk getting a higher price for hotel reservations. ${ }^{7}$

The next subsection presents the main questions that are addressed by this thesis and the following structure (1.2). Next, I outline the legal method (1.3), the working definitions (1.4), and the legal prerequisites necessary for answering the questions (1.5).

\subsection{The questions to be addressed and the structure of the thesis}

This thesis examines three legal schemes that regulate automated decisions based on profiling. The first is Article 15 of the DPD as mentioned in subsection 1.1. Secondly, I look at the implementation of the Directive under Norwegian law, namely section 25 of the Norwegian Personal Data Act. Lastly, the thesis analyzes Article 22 of the General Data Protection Regulation (GDPR), which will replace the DPD. The GDPR entered into force the $25^{\text {th }}$ May 2016, and will be in effect as of the $25^{\text {th }}$ May $2018 .^{8}$

Korff has characterized Article 15 as a dead letter. ${ }^{9}$ One only has to look at the lack of case law. ${ }^{10}$ This might appear strange to a practitioner of data protection law, as automated decisions and profiling have become so widespread. It is presumably not for the lack of important decisions made by computers, as the examples above shows.

Thus, the first main question is under what conditions Article 15 applies. The answer to this question does not take a 'yes' or 'no' form; instead, I explore the possible application of the provision through actual cases of automated decisions. The assessment of the law follows a dogmatic method. EU Directives rely on national implementation for their application in the Member States legal orders. ${ }^{11}$ Thus, I do not intend the term application, in question one, to be understood in a strict sense. It does not ask how Article 15 might be applied directly in

$6 \quad$ Duhigg (2012) pp. 182-215.

7 According to Mattioli (2012) Mac-users can be willing to pay up to $30 \%$ more for a hotel reservation than the average price.

8 Article 99 GDPR.

9 Korff (2012) p. 26.

10 I have personally not been able to identify a case where the provision has been applied, in any of the Member States to the EU nor in the contracting parties to the European Free Trade Association (EFTA). However, I have only looked at online legal databases that are translated to English. See also Borgesius (2015) p. 374 and Bosco (2014) p. 25.

11 Craig (2011) p. 106. A reservation has to be made for provisions with direct effect, such as Article 7 (f) of the DPD following C-468/10 ASNEF p. 22 (55). The same requirement is essentially demanded of the EFTA-countries under EEA-agreement, with some modifications, see Sejersted (2011) pp. 195-196. 
disputes $^{12}$, but rather aims at answering what obligations the Member States of the EU have under Article 15.

A closely related question is what level of harmonization the Directive requires between the Member States of the EU and the contracting parties to the European Economic Area agreement (EEA). ${ }^{13}$ There is great diversity in the implementation of Article $15 .{ }^{14}$ Some Member States have viewed the Directive as providing a minimum level of protection, and thus given some provision that provides a higher level of protection than the equivalent provision in the DPD. ${ }^{15}$ By a higher level of protection, I refer to giving the citizens better safeguards against the processing of their personal data at the expense of free flow of data between the Member States. ${ }^{16}$

The level of protection offered by section 25 of the Norwegian Act might be higher than the Article 15, as Norwegian lawmakers used a different wording from that of the original text. ${ }^{17}$ Consequently, the thesis illustrates the requirement of harmonization of Article 15 through a study of the Norwegian transposition of the Directive. The second question in this thesis is thus whether the Directive requires a complete or minimum level harmonization of Article 15, and what consequences this requirement has for the interpretation of section 25 of the Norwegian Act.

The third question is whether Article 22 of the GDPR offers a higher level of protection than required by Article 15 of the DPD. Similar to the examination of Article 15, this question will analyze the GDPR in a dogmatic manner and apply the interpretation to examples of automated decisions. It is thus necessary to outline what sample cases I will look at.

The following six examples serve as a model for comparing Article 15 DPD and Article 22 GDPR. It is in online environments that technology has permitted the automation of decision making based on profiling. ${ }^{18}$ Thus all the examples stem from Internet services. This includes

12 The distinction is summarized in Prechal (2005) p. 6.

13 In addition to the Member States to the EU, the EEA agreement includes Norway, Island and Lichtenstein.

14 Korff (2002) pp. 112-116.

15 Such as Spain in relation to Article 10(2)b of the Spanish Royal Decree 1720/2007that provided a higher level of protection than Article 7(f) of the DPD. See C-468/10 ASNEF.

16 Article 1(2) DPD.

17 A different wording in itself does not necessarily mean that the scope of the provision is different, as it has to be measured against other sources of law, and what requirements EU/EEA provides.

18 This is not to say that automation of decision-making cannot happen without the use of the Internet. It is nevertheless hard to find examples of automation based on profiling that is purely computerized outside the online environment. Online data is widely available as input for automated decision. See Davenport (2005) p. 4. 
automated scoring techniques, such as credit scoring for (1) bank loans, (2) automated insurance underwriting, (3) granting of credit in an online shop, but also automated scoring for the purposes of (4) e-recruiting ${ }^{19}$. The thesis will also use (5) weblining ${ }^{20}$ and (6) online behavioral advertising ${ }^{21}(\mathrm{OBA})$.

All of these examples involve relatively simple tasks that companies have automated for the primary purpose of saving personnel costs. By contrast, the application of Article 15 of the DPD and Article 22 of the GDPR seek to incorporate human involvement into important decision-making if the decisions have legal or significant consequences (this is subjected to certain qualifications as examined in chapter 2 and 6). ${ }^{22}$

A possible consequence of applying Article 15 and 22 to the abovementioned examples might, therefore, be that banks, online shops, and online marketers will bear the burden of a higher transaction cost, as they would have to employ personnel in the decision making. ${ }^{23}$ This could, in turn, make the application of Article 15 and 22 a de facto prohibition of profiling for the purposes of automated credit scoring, e-recruiting, and behavioral advertisement, as such practice would not be profitable. ${ }^{24}$

The six examples given above are mostly activities conducted by private companies. This thesis does not address automated decisions made by governments and other administrative organization. Most Member States of the EU presumably have administrative laws that give their citizens the right to contest administrative decisions ${ }^{25}$, which would to a great extent make Article 15 and 22 superfluous.

19 E-recruiting is in this thesis understood as the automated ranking of job applicants, which in turn can be used to automatically turn down people for a job position. See Faliagka (2012) p. 557.

20 In this thesis weblining refers to two forms of differentiation of content on the internet, namely price differentiation and search differentiation. The word is inspired by the term redlining. "Call it Weblining, an Information Age version of that nasty old practice of redlining, where lenders and other businesses mark whole neighborhoods off-limits. Cyberspace doesn't have any real geography, but that's no impediment to Weblining." Stepanek (2000).

21 OBA is customized advertisement to a person based on his or her online profile. See Leon (2012).

22 Subsection 2.2 and 6.3.3 covers the nature of the right in Article 15 and Article 22.

23 Transaction cost is understood as the cost connected to an economic exchange, such as the cost of negotiating a contract. If an online bank would be forced to employ personnel in every loan application it would also increase the cost of the granting of loans, because they in fact would have to employ more personnel. Eide (2008) p. 129.

24 The possible economic consequences of the use of these provisions will be expanded on in the concluding remarks (chapter 7).

25 E.g. section 28 to the Norwegian Public Administration Act. 
This thesis sits in the legal landscape of data protection law. The regulatory framework regarding profiling and automated decisions has parallels and similarities to other legal fields, such as consumer protection law, discrimination law, e-commerce law, and finance law. I will not examine these other legal fields to any great extent. However, I mention these legal fields when it is necessary to understand the practicality of the provisions.

The subject in the next three chapters is Article 15. Chapter 2 interprets the right under Article 15(1). Chapter 3 examines the possibility of derogations from the right in Article 15(2). Finally, chapter 4 applies Article 15 of the abovementioned examples of profiling and automated decisions. Thus, chapters 2 and 3 will be more abstract in character, as they deal with the interpretation - and not the application - of Article 15(1) and (2). In chapter 5 I analyze the Norwegian implementation of Article 15 and chapter 6 deals with Article 22 of the GDPR. Chapter 7 offers some closing remarks.

\subsection{Legal method}

This thesis is in part an exercise in interpreting legislation, as there is no case law from the CJEU regarding Article 15. The examination of the law can become too abstract without a foothold in a practical scenario. This thesis seeks to remedy this shortcoming by using documented examples of automated decisions and profiling in real life.

The lack of case law also means that the number of legal sources is limited. This thesis will mostly make use of the wording in the legislation, the purpose of the provisions, preparatory works, commentaries and opinions from international actors, and legal literature. However, the method of interpreting the legislation will be different for the two legal frameworks assessed in this thesis, namely Norwegian law (chapter 5) and EU law (the rest of the thesis). The principles of interpretation will be different, as well as the relevant sources of law and the weighing of these sources.

The starting point for examining EU law is the method used by the European Court of Justice (CJEU). ${ }^{26}$ In 1981 the CILFIT doctrine summarized this method of interpretation, which takes a teleological approach. ${ }^{27}$ The legislative history does not have much weight in EU law. ${ }^{28}$ It is

26 The CJEU shall «ensure that in the interpretation and application of the Treaties the law is observed", under Article 19 of the Treaty on the European Union (TEU). The competence of the Court is among other things to give preliminary rulings under Article 19(3)b and Article 267 of the Treaty on the Functioning of the European Union (TFEU). This is in practice the way a case concerning Article 15 would be laid down for the CJEU.

27 C-283/81 CILFIT. This thesis also relies on a more extensively summary of the method used by the CJEU in Fredriksen (2012) p. 190-231.

28 Arnesen (2015) p. 37. 
nonetheless of use to illustrate the purpose of the legislation, and especially when there are not many sources available in the interpretation. The CJEU makes also extensive use of the principle of effet utile, which is of particular interest for the interpretation of Article 15 in chapter 2 and $3 .^{29}$ This principle stipulates that where a provision is open to several interpretations, "preference must be given to that interpretation which ensures that the provision retains its effectiveness." $" 30$

EU legislation has several authentic language version, and these must consequently be compared when interpreting Article 15 and Article $22 .{ }^{31}$ In this thesis, the starting point is taken in the English versions, and compared against other language versions where necessary.

Chapter 5 makes use of the method developed by the Norwegian Supreme Court and described in legal literature. The method utilized by the CJEU differs from the Norwegian methodology especially in the CJEU's disregard of the wording, the preparatory works and its emphasis on the original purpose of the law. ${ }^{32}$

It is important to note that Norway is not a member state of the EU but of the EFTA ${ }^{33}$, which is associated with the EU through the EEA-agreement. The legal answers provided by the interpretation of the EU law alone, after the method of the CJEU, will therefore not bind Norway directly.

This is, however, only an in-principle point of departure for the significance of EU law in Norway, as case law from the Norwegian Supreme Court and the EFTA-court shows that case law from the CJEU will bear a great deal of weight in EEA-law. ${ }^{34}$ I come back to these methodological issues in chapter 5 (concerning the Norwegian implementation of Article 15).

\subsection{Profiling and other working definitions}

Profiling is now defined in Article 4(4) to the GDPR. The term is not used explicitly in the DPD, but it can still be interpreted as part of Article 15 with some modifications. I return to these definitions of profiling in chapter 2 and chapter 6 , as they form one of the legal condi-

29 Fredriksen (2012) p. 212.

30 Joined Cases C-402/07 and C-432/07 (recital 47) and ibid.

31 C-283/81 CILFIT (recital 18).

32 Arnesen (2015) p. 29.

33 The Member States are Switzerland, Island, Liechtenstein and Norway. Switzerland is however, not part of the EEA-agreement.

34 E.g. Rt-2006-1473 (recital 62) and Fredriksen (2011) pp. 238-239. Norwegian law is based on a dualistic view of the national legal system and the countries international commitments. I return to this and the issue of the principle harmonious interpretation in chapter 5 . 
tions in the provisions. This subsection shall instead provide the technical explanation for profiling and other working definition used in this thesis.

Profiling is a buzzword used in many aspects of society and not always with a clearly defined meaning. Hildebrandt has described profiling as the result of a process of data mining:

"Data mining [...] is a procedure by which large databases are mined by means of algorithms for patterns of correlations between data." 35

Instead of data mining, some legal scholars use the term knowledge discovery in databases (KDD process) ${ }^{36}$, where data mining is included as one of its five steps. ${ }^{37}$ The similarity between these explanations is that profiling is done by finding correlations in data by the use of automated means (e.g. algorithms). This definition, however, only describes the means of profiling. A more substance-oriented definition is made by Dinant, who explains profiling as a computerized method that makes it possible to "place individuals, with a certain degree of probability, and hence with a certain induced error rate, in a particular category in order to take individuals decisions relating to them." 38

An example would be to place a person in a sports enthusiast category (because an analysis of his data indicates that he is a sports fan) and thus give that person offers on gym equipment. In other words, profiling stereotypes individuals through computer predictions.

The analysis of a person can culminate in data. Data is also a part of the concept of personal data, which is the scope of the DPD and the GDPR. ${ }^{39}$ The Oxford Dictionaries define data as:

"quantitates, characters, or symbols on which operations are performed by a computer, which may be stored and transmitted in the form of electrical signals and recorded on magnetic, optical, or mechanical recording media." 40

Several legal commentators in the area of data protection law have used this definition and slight variations of it. ${ }^{41}$ Data is personal if it relates to an "identified or identifiable natural

\footnotetext{
35 Hildebrandt (2008) p. 18.

36 E.g. Custers (2004) p. 19.

37 The KDD process generally consists of five steps: data collection, data preparation, data mining, data interpretation, and lastly application of the data. See Custers (2004) pp. 17-23 and 35-80

38 Dinant (2008) p. 5 and inspired by King (2008) p. 145. See also Schreurs (2008) p. 241.

39 Article 3(1) DPD and Article 2(1) GDPR.

40 Oxford Dictionaries (2016).
} 
person," 42 meaning if a person can be identified, either directly or indirectly, on the basis of the data collected. ${ }^{43}$ Loan and insurance applications, e-recruiting, and other types of credit scoring will always require the processing of personal data, as insurance companies and future employers need to know the person's identity and other information to conduct the requested services.

The same cannot be said for practices such as weblining and online behavioral advertising. Identification of the person targeted by such decisions is not necessary for practices of price differentiation and individualized commercials. However, in reality, one does not need to know many attributes about an individual before that person can be identified. The Article 29 Working Party, an advisory group to the national data protection authorities, has argued that data collected for behavioral analysis and advertising is personal data. ${ }^{44}$ This includes, for example, the collection of IP addresses. ${ }^{45}$ This thesis presumes that such identification has been made.

By tracking a person across websites, one can collect data such as demographic data, locational data, technical data, psychographic data, predictive data, behavior data, and life events. ${ }^{46}$ All this data can be used to construct a profile of the person, which can form the basis of decisions about them, like showing a specific commercial or an offer for a product.

Data does not necessarily make any sense on its own, but once translated or otherwise processed by a computer it can become information. Information is, therefore, the "meaning (semantic content) assigned to data." 47

Data subject refers to the person to whom the data relates, while data controller is the entity which determines the purposes and means of the processing of personal data. ${ }^{48} \mathrm{~A}$ data proces-

41 E.g. Udsen (2009) p. 34 and Bing (1982) p. 66.

42 Article 2(a) DPD.

43 A person is identified if one has the information of the person's physical, mental, economic, cultural or social identity under Article 2(a). In this assessment one needs to consider all the means "likely reasonably to be used" according to recital 26 of the preamble. This is explained to a larger extent in WP 136. The Working Party is an advisory group to the European Commission. However, the Working Party has issued many opinions and recommendations and their opinions have influence in how European data protection law is interpreted and practiced in the Member States. See Schartum (2011) pp. 98-99.

44 See WP 171 p. 3.

45 See WP 171 p. 7. See also Datatilsynet (2015) pp. 25 and 28-29.

46 Datatilsynet (2015) pp. 23-25.

47 Bygrave (2015b) p. 95.

48 Article 2(a) and (d) DPD 
sor is someone who processes the data on the data controller's behalf. ${ }^{49}$ The DPD defines the processing of personal data quite broadly, as it shall mean "any operation or set of operations that is performed upon personal data." personal data, from its collection to storage and usage.

\subsection{Legal prerequisites}

Profiling is in principle regulated throughout the data protection legislation before a decision happens, as it is processing of personal data. This subsection gives a short overview of the legal prerequisites that must be in place before the application of Article 15 is possible.

In a broad sense, everyone has the right to obtain information and use it as they see fit, as this is a requisite for freedom of expression. Thus, European data protection law constitutes an exception, as it restricts processing of personal data. ${ }^{51}$

The data controller must have legitimate grounds for the processing of personal data in order to render the activity legal. There are several legal grounds, but most practical for profiling and automated decision making is consent from the person concerned or if the processing is necessary for the purpose of legitimate interests pursued by the data controller. ${ }^{52}$ This thesis assumes that the data controller has obtained legal grounds for the data processing.

In addition, several principles of processing personal data require compliance in order for the profiling to be legal, such as the requirement of data quality and purpose specification. ${ }^{53}$ The data subject has the right to have inaccurate and incomplete data of his rectified, erased, and blocked, according to Article 12(b). However, regarding the chronology of events, Article 12 applies to the processing of personal data before any decision making, whereas Article 15 regulates decisions resulting from the data processing.

Furthermore, under Article 10 and 11 of the DPD, the data subject has the right to obtain information about the processing conducted by the data controller. The person concerned also has a right to gain access to the logic involved in the automated processing that leads to the decisions, which Article 15 stipulates. ${ }^{54}$ This right under Article 15 is not helpful if the data

\footnotetext{
49 Article 2(e) DPD.

50 Article 2(b) DPD.

51 Exceptions are made for processing of personal data for personal use, and the processing done for the purpose of public security, defense, and State security and in areas of criminal law, under Article 3 (2) DPD.

52 Article 7(a) and (f) DPD.

53 Article 6(b) and (d).

54 Article 12 (a) third bullet point DPD.
} 
controller has not adequately informed the individual of the profiling or the individual's right to resist the automated decision. This thesis will however not cover these rights to any great extent.

Finally, Article 14 of the DPD gives the data subject a right to object to the processing of his personal data. This raises the question of whether there is a need for the right to not be subject to decisions based on data processing when one could oppose such processing in the first place.

A difference between the Article 15 and Article 14 is that the scope of the latter provision extends to the processing of personal data, while Article 15 applies to the use of the data as a decision. One can argue that it is already too late to object to a prior processing activity after the decision-making process has concluded. One can also claim that the data subject often wants the automated processing to happen but will use Article 15 if he is not happy with the end result, e.g., not getting a loan, job, or insurance policy. ${ }^{55}$

55 There are no conditions for objecting to processing that happens for the purpose of direct marketing under Article 14 (2). This right could to some degree eliminate the need for Article 15 when it comes to online behavioral advertising (chapter 4). But as explained above, once a decision has fallen, in this case when OBA has happened, it could be more practical to contest the decision and not only the processing. 


\section{$2 \quad$ Article 15(1) of the DPD}

\subsection{Introduction}

The EU Data Protection Directive of 1995 obligated the Member States of the EU to give their citizens the right not to be subject to automated decisions based on profiling. ${ }^{56}$ Article 15(1) gives this right, for which the Article's second paragraph gives exceptions:

1. Member States shall grant the right to every person not to be subject to a decision which produces legal effects concerning him or significantly affects him and which is based solely on automated processing of data intended to evaluate certain personal aspects relating to him, such as his performance at work, creditworthiness, reliability, conduct, etc.

2. Subject to the other Articles of this Directive, Member States shall provide that a person may be subjected to a decision of the kind referred to in paragraph 1 if that decision: (a) is taken in the course of the entering into or performance of a contract, provided the request for the entering into or the performance of the contract, lodged by the data subject, has been satisfied or that there are suitable measures to safeguard his legitimate interests, such as arrangements allowing him to put his point of view; or

(b) is authorized by a law which also lays down measures to safeguard the data subject's legitimate interests.

Article 15 was the very first attempt at regulating purely machine-based decisions in an international context. ${ }^{57}$ In some ways, one may regard it as an attempt by lawmakers to frame the futuristic ideas of both profiling and automated decision making - technological advances that were yet to come. It is therefore not surprising that Article 15 consists of broad formulations.

There are several ways of systemizing Article 15, especially because of its vagueness. The number of conditions the provision consists of and what to name those conditions are questions about how to best systemize the Article, and they do not affect the substantive content of

56 Article 15 does not use the term profile, but the more strenuous "automated processing of data intended to evaluate certain personal aspects relating to him". However, as will be examined in subsection 2.4, profile or personality, is an easier term for explaining the content of the condition.

57 Bygrave (2001) p. 17. The Convention for the Protection of Individuals with regard to Automatic Processing of Personal Data (CETS 108) under the Council of Europe is currently in revision and will most likely adopt a provision on profiling. See CM/Rec (2010)13. Article 15 is sought continued in Article 22 of the GDPR and Article 11 to the Data Protection Directive in Police and Criminal Justice sector (2016/680). 
the provision. This thesis divides the Article up into three different conditions, in which one of the conditions has two alternatives (subsection 2.6). ${ }^{58}$

The first requirement is that an automated process with the intention of evaluating certain personal aspects of the data subject has taken place (subsection 2.4). This condition is in this thesis called the profiling condition. Secondly, an automated decision must have followed and be based on the profiling (subsection 2.5). ${ }^{59}$ The fourth subsection assesses two alternative conditions, as the decision either must have had legal effects for the data subject or it must have significantly affected the person (subsection 2.6). After the assessment of the substantive content of Article 15, I will give a short account of who has rights and who has obligations under the provision (2.7). ${ }^{60}$

58 Some legal commentators divides the provision into four conditions, like Bygrave (2001). However, the European Commission, in their commentary to the amended proposal to the Article, divided it into three conditions. COM 422 (1992) p. 26.

59 The requirement of there being a "decision" and that this decision is based "solely" on an automated process could have been assessed separately. The conditions are however so interrelated that little would be gained by giving separate accounts for them. It could also have been appropriate to examine the decision criterion prior to the profiling-condition. But I fear that the concept of "decision" is too abstract without first knowing what the basis for it has to be, namely profiling of the data subject.

60 As I examine the conditions one by one, the examples I use to illustrate the scope and the content of the conditions does not necessarily fall within the Article as a whole. This is for instance the case when I use web commercials to illustrate profiling and automated decision making. Such commercials do not necessarily fulfill the condition of "significant" consequences. 
The following figure summarizes the structure of Article 15:

Automated processing of data with the intention of evaluating personal aspects relating to a person (profiling- condition)

Subsection 2.4

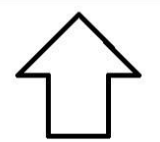

Based solely (subsection 2.5.2)

Automated decision (subsection 2.5)

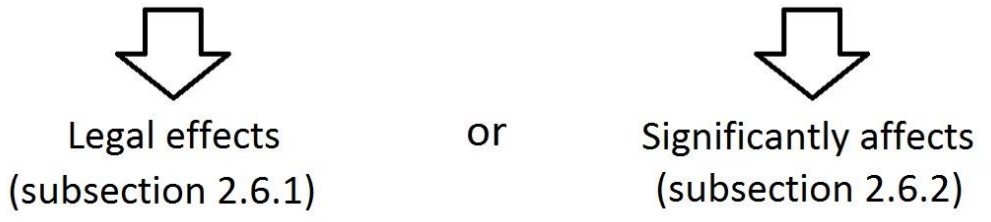

Figure 1

However, before going into the conditions that make up the provision, I first examine what the right under the provision actually entails, namely the right of human re-examination (2.2). I examine quite extensively the rationale behind Article 15, as this will aid the interpretation of the conditions (2.3).

\subsection{The content of the right: human re-examination}

Two questions require answering: (1) what does the right under Article 15 obligate the decision maker to do, and (2) does the right under the provision need to be exercised? The first question is about the content of the right, and the second is about the procedure for applying the right.

In its literary sense the wording of "not to be subject" means that the person concerned has the right not to be bound by a decision. This could, for instance, be the case if an automated system deprives a person of his welfare benefits because of fraud. ${ }^{61}$ However, this is not the same

61 BigInsight in Oslo is currently researching the possibility of detecting such frauds. See Vogt (2015). 
as saying the person will have the right to keep his benefits, as the government just needs to make the decision again, only this time with human oversight. Thus, the rights under Article 15 will de facto demand human re-examination.

However, understanding Article 15 as a right of not being bound by a decision does not make sense for decisions without legal consequences. A person could try exercising a right of not being bound by a refusal for a loan, but the bank would presumably be indifferent to such a demand. Article 15 does not force the bank to change the outcome of such a decision, even if it was objectively wrong. ${ }^{62}$

Consequently, the provision should be understood as providing the right of human reexamination also for decisions without legal impact (but which has significant consequence). Another possible solution is to read Article 15 as providing a prohibition of computer made decisions with significant effects. However, the decision maker only needs to make the decision again, just this time with human involvement. The provision will, therefore, de facto work as a right to demand human participation in a re-examination of the decision. Thus, the answer to the first question is that the right under Article 15 obligates the decision maker to involve human thought in a re-examination of the decision.

The second question is whether the data subject must demand human involvement, or if Article 15 , in fact, should be interpreted as a prohibition. No matter what is required by the Article, the content of the right will work as a right of human re-examination. The wording of "Member States shall grant the right to every person not to be subject to a decision" could be understood in both ways. Neither the preamble nor the preparatory works contain statements relevant to answering this question.

There is disagreement in legal literature concerning this question. Bygrave understands the provision as leaving the actual exercise of the right up to each individual ${ }^{63}$, while Gutwirth and De Hert sees it as a prohibition. ${ }^{64}$ However, a third possible interpretation is to leave the understanding of the right to the national discretion of the Member States. Directives require implementation into national legislation before it can protect citizens. ${ }^{65}$ The lawmakers can

62 Öman (2011) p. 428. This is on the other hand just of theoretical interest, as private businesses would likely change the decision if it were objectively wrong. It would normally be bad both for the income and the reputation of the business.

63 Bygrave (2001) p. 18. Supported by Bosco (2015) p. 16.

64 Gutwirth (2008) p. 283. Also supported by Korff (2005) p. 49. The discussion is summarized in Borgesius (2015) p. 375.

65 An exception has to be made for provisions with direct effect. See footnote 11. 
formulate Directives ambiguously to leave the Member States some discretion in the implementation of it. ${ }^{66}$

There is diversity in the implementation of the provision among the Member States. ${ }^{67}$ Germany ${ }^{68}$ and France ${ }^{69}$, for example, have implemented the provision as a prohibition, while the UK has given the data subject a right not to be subject to automated decisions ${ }^{70}$, and still other jurisdictions like Norway have established an explicit right to demand human involvement. ${ }^{71}$ The practice of the Member States is not an argument with much weight in the interpretation of the Directive, but it illustrates the fact that the wording is equivocal. The answer to the second question is therefore that it is up to the Member States whether Article 15(1) should be implemented as a prohibition or not.

\subsection{The rationale behind Article 15}

The aim of Article 15 is to give persons a right to not be subject to important decisions regarding themselves, as long as a computer made the decision based on the profiling of the individual. But the rationale behind this right does not give itself.

It is worth emphasizing that the Article is not directed at the actual profiling process; it is the decisions following profiling that the Article gives a right to not be subjected to. When the Article gives the individual concerned a right not to be subject to a computerized decision, it is not so much the decision itself that is contested but the method and technique used to make the decision.

However, one may also claim that part of the Article's rationale is an innate skepticism towards automated decisions, as the alternative to automated processing is human processing. A right to not be subject to a computerized decision will therefore in practice work as a way to contest the quality and correctness of such a decision.

According to the preparatory works, the provision arises from two different yet interrelated concerns: (1) the evolution of data mining, profiling, and how much information can be ex-

\footnotetext{
66 Young (2015) p. 63.

67 Korff (2002) pp. 112-116.

68 Section 6a to the German Data Protection Act (2003).

69 Section 10 to the French Data Protection Act (1978).

70 Section 12 of the Data protection Act (1998). The UK has also given quite detailed Regulation when it comes to the procedure of demanding human involvement in the decision making.

71 Section 25 to the Norwegian Data Protection Act (2000).
} 
tracted from metadata, and (2) the evolution of computerized decisions. ${ }^{72}$ The decisionmaking condition and the profiling condition are therefore the two main components of the Article, even though the provision has three separate conditions.

The EU could have dealt with the above-mentioned concerns in two separate Articles, the first dealing with the creation of profiles and the second giving the right to oppose automated decisions. It makes sense that the EU did not want to give data subjects a right to oppose all automatic decisions, as computerized decisions are part of many practical activities in the world today. Therefore, one may assume that the lawmakers did not regard automated decisions as invasive enough for individuals to require its own provision.

The EU's decision not to regulate the creation and application of profiles independently, however, makes the Article less effective to combat profiling. However, one can claim that other provisions adequately control the creation of profiles, rules like the necessity of having legitimate grounds for processing the data, the purpose limitation principle, etc. ${ }^{73}$

As human involvement is the effect of applying Article 15, the provision must have a premise that humans can, in fact, assess data differently than computers. An obvious difference between human decision making and machine-based operations is that persons have feelings and can exercise discretionary assessments. Persons have the ability to see the positive or negative effects of a decision, which could cause the person to take other factors into account when making the decision.

Consequently, one can claim that the Article does not intend to produce automated decisions that, in fact, are as correct as possible. If the lawmakers concerned themselves with what a correct decision was, then the provision would have dealt with a right to re-examination without regard to whether it was a machine or a person that did the re-examination. Therefore, it can be argued that the provision's purpose involves as much human dignity and sympathetic decision making.

The following gives an overview of the different ideas behind the provision that do not stem from the wording itself, but from the historical background and the preparatory works.

72 COM 422 (1992) p. 26.

73 See subsection 1.5. 
According to the preparatory works ${ }^{74}$, the right under Article 15 was inspired by a similar right in French legislation, namely Article 2 of the Act on Information Technology, Data Files and Civil Liberties of $1978 .{ }^{75}$ The French Act was amended in $2004 .^{76}$ Translated into English the Article reads as follows:

No judicial decision involving an appraisal of human conduct may be based on any automatic processing of data which describes the profile or personality of the citizen concerned.

No governmental or private decision involving an appraisal of human conduct may be based solely on any automatic processing of data which describes the profile or personality of the citizen concerned. ${ }^{77}$

The French provision has the character of being an administrative rule, as it concerns the automation of court decisions. They could have regulated judicial decisions together with other types of decisions. This seems to have rubbed off on the design of Article 15. In the first proposal to the Directive, the data subject had the right to object to "administrative or private decisions" $" 78$ This fear of robot judges can therefore be seen as the origins of the provision.

In legal literature concerning the European data protection principles, the right to object to special forms of processing has been perceived as originating from the principle of the data subject's participating influence. Bygrave describes it as:

"A core principle of data privacy laws is that persons should be able to participate in, and have a measure of influence over, the processing of data on them by others."79

In their communication to the first proposal, the Commission stated that the principle of the data subject's influence is a part of the rationale behind Article $15^{80}$ :

74 The Economic and Social Committee to the first proposal for the Directive. See C159/14 (1991) point 2.2.11.1.

75 The provision is after the amendment of 2004 situated in Article 10. The original version is found here (in French): $\langle$ https://www.legifrance.gouv.fr/jo_pdf.do?id=JORFTEXT000000886460 > last accessed 25.05.2016.

76 The current French provision is limited to decisions that have legal effects for the data subject, and does not give the data subject a right to oppose decision with significant consequences. Thus, the French act offers a lower level of protection that the DPD, and it should be interpreted in conformity with EU-law. See subsection 5.1.

77 Translation is taken from Bygrave (2001) footnote 2. See also Simitis (1992).

$78 \operatorname{COM}(90) 314$ final - SYN 287

79 Bygrave (2014) p. 158. 
"This provision is designed to protect the interest of the data subject in participating in the making of decisions which are of importance to him. The use of extensive data profiles of individuals by powerful public and private institutions deprives the individual of the capacity to influence decision-making processes within those institutions, should decisions be taken on the sole basis of his "data shadow.",81

But the principle does not entirely cover the right given in Article 15, because as previously mentioned, the provision does not provide a right to object to the processing of personal data but the right not to be subject to a decision that arises from the processing of the data subject's profile. We may nevertheless understand Article 15 as the right to have the decision reexamined by $a$ person. And one can argue that the actual effect of the right to oppose automated decisions - indirect control over the processing - makes the provision similar to other rules that have origins in the principle of participating influence. In legal literature arguments have also arisen claiming that the provision in itself expresses a new principle and not just a side of the individual participating principle. ${ }^{82}$

The preparatory works of the amended proposal, in commentary by the Commission, highlight one other issue that the previous preparatory works did not address, namely to what degree humans would abandon their responsibility by having a computer make their decisions:

"The danger of the misuse of data processing in decision-making may become a major problem in the future: the result produced by the machine using more and more sophisticated software, and even expert systems, has an apparently objective and incontrovertible character to which a human decision-maker may attach too much weight, thus abdicating his own responsibilities."

I personally fail to see the reasoning this argument, as the provision - also the amended proposal that was not passed - has a scope that does not encompass decisions involving a human decision maker. There is no scenario in which the provision will deter a human from attaching

80 The first proposal had mostly the same structure and conditions as the current Article 15. See C 277/03 (1990).

81 COM 314 (1990) p. 29.

82 This stance is taken by Bygrave (2014) p. 168, where he also gives a notion that the individual participating principle does not fully cover the background for the Article. "The latter right [Article 15] could well be treated as the basis for a nascent data privacy principle - namely that fully automated assessments of a person's character should not form the sole basis of decisions that significantly impinge upon the person's interests." This is also supported by Blume (2008) p. 294.

83 COM 442 (1992) p. 26. 
too much weight to the automated process, as the Article only applies to decisions "solely" based on an automated process.

However, the provision can send a signal to the industry and to governments that one should not always trust decisions made by computers alone, therefore giving them an incentive to have persons review the automated process before the decision is made.

Human rights will always form a backdrop when assessing privacy issues. ${ }^{84}$ Profiling in the context of automated decisions has, however, not been at the center of the human rights conversation. Yet, some legal literature has treated profiling in connection with discrimination law. ${ }^{85}$ Discrimination can be an argument to what is considered significant decisions. Chapter 4 covers this issue.

In summary, one can argue that the rationale behind Article 15 is diverse. The provision tries to deal with two concerns, namely the continuing growth of automated decision making and profiling, and it does so by targeting the most important decisions. Neither an automated decision nor profiling is too intrusive on its own to require separate regulation. The principle of participation is only partly a reason for having the provision, as the right under the Article mainly targets decisions. The lawmakers see a human presence in important decisions as positive, but that does not necessarily make the decisions more correct.

\subsection{Condition 1: Profiling as a basis for decision-making}

\subsubsection{Automated processing}

This condition involves the requirements for what may constitute the basis for automated decisions as governed by Article 15. It consists of two components, namely (1) "automated processing" of data (2) intended to "evaluate certain personal aspects" of the data subject. The latter component is what makes Article 15 the profiling condition, which I assess in 2.2.1. First, however, I will examine the terms "automation" and "processing."

As covered in subsection 1.4, the definition of 'processing' comprises almost every aspect of handling data. ${ }^{86}$ To make automated decisions that target individuals, the decision maker must by necessity collect, store and use personal data. The condition does therefore not cause much difficulty.

84 Recital 10 in the preamle of the DPD excplicitly recognizes Article 8 (the right of privacy) of the European Convention for the Protection of Human Rights as fundamental right.

85 Schermer (2013) pp. 138-140.

${ }^{86}$ Article 2 (b) DPD. 
Neither does the requirement of automation cause any trouble. Automated processing is not defined in the Directive. But the term automated processing is usually used in contrast to manual processing. If a computer stores personal data, as the databases of an insurance company, it is called automated processing. For illustration, the German Federal Data Protection Law maintains this distinction between automated and manual, and defines "automated processing" as the:

"collection, processing or use of personal data by means of data processing systems. A non-automated filing system is any non-automated collection of personal data which is similarly structured and which can be accessed and evaluated according to specific characteristics". ${ }^{87}$

Summarized, "automated processing" means basically that a machine must do the work and not a person. The automated generation of online advertisement which targets individuals with commercials and offers based on their behavioral data, will for instance fall within the scope of this wording.

\subsubsection{Intention to evaluate certain personal aspects}

Decisions, as regulated by Article 15, cannot be based on any automated processing, but is limited to the automated processing of data intended to evaluate certain personal aspects relating to the data subject. The Article subsequently lists examples of such automated processes: "performance at work, creditworthiness, reliability, conduct, etc."

First, I examine the criterion of certain personal aspects, and how this is different a conventional process of personal data. Secondly, this subsection looks at what is meant by automated processing with the intention of evaluating these certain personal aspects.

The wording of certain personal aspects is vague. Any personal data could potentially represent a certain aspect of an individual. But it must be presumed that the lawmakers only considered some types of data to fall within the scope of the Article, such as creditworthiness or job performance, which the Article explicitly mentions.

Many of the other language versions use variations of the term personality, instead of the English personal aspects. The Spanish translation, for instance, says "aspectos de su personalidad", the French "certain aspects de sa personnalité" and the Danish version

87 Section 3 (2) to the German Federal Data Protection Act. Presumably, the Member States are in accordance with what is understood by automation as opposed to manual processing of data. A similar definition of automated processing is also used in Article 2 (c) to CETS 108. 
"bestemte personlige forhold". ${ }^{88}$ The comparison between the language versions carries a great deal of weight in the interpretation of Article $15 .^{89}$ Thus, it seems as the criterion of certain personal aspects should be read as automated processes that describe the data subject's personality. This is also concluded by Bygrave:

"There is no doubt that the phrase 'personal aspects' refers to aspects of the data subject's person or personality." 90

The historical background of Article 15 also supports this interpretation. The first and the amended proposal of the Directive used the expressions "defining his profile or personality" and "defining a personality profile" instead of the more ambiguous certain personal aspects. ${ }^{91}$

A person's behavior, values and ideas usually come to mind when considering a person's personality. Other examples can, for instance, be a preference in clothing, food, and entertainment. But more superficial characteristics of a person, like a person's sex or age, are not typically associated with personality.

The preparatory works use the information of a person's bankroll as an example of data that does not constitute certain personal aspects relating to him. This is presumably, because this kind of information is more an objective aspect of that person and does not really define his personality:

“(...) this excludes all cases were the system does not define a personality profile: for example, the fact that a person is unable to obtain the sum of money he wants from an automatic cash dispenser because he has exceeded his credit limit would not fall inside this definition." 92

Korff concurs, and distinguishes between decisions made on the basis of "straightforward factual data" and processing activities that are more "subjective." 93 Hence, the use of statistical data applied in individual cases might fall outside the scope of the provision:

\footnotetext{
88 The wording of the German and the Swedish version is also closer to the term "personality" than personal aspects.

89 C-283/81 CILFIT (recital 18).

90 Bygrave (2001) p. 20.

$91 \operatorname{COM}(90) 314$ final - SYN 287 and COM(92) 422 final - SYN 287

92 COM 442 (1992) p. 26.

93 Korff (2005) p. 49.
} 
"Thus, the use of age as a factor in health insurance, while, of course, relating to probability rather than an individual certainty, would appear to be uncontroversial." 94

It is not possible to clearly draw a line between personal data that describes a personality and data that does not. However, some factors in this assessment can be laid out. One should first look at the information output. Maybe knowing the domicile of a person is not information relating to his personality, but if his place of residence at the same time can tell us something about his income level, then we may start to build a profile about that individual. This is, in essence, applying stereotypes to the data collected about an individual.

Secondly, one should look at the data input. Age might not be a subjective type of data in the sense of Article 15, as in Korff's example, but medical history might be. The Directive distinguishes between personal data that is sensitive and non-sensitive. ${ }^{95}$ Data concerning racial or ethnic origin, political opinions, religious or philosophical beliefs, trade union membership, health, and sex life are the categories the Directive considers to be sensitive. The collection of sensitive data generally is subject to stricter regulations than that of regular personal data. It can be argued that if the automated process has taken sensitive data into account, then it should not take such an extensive profile before one can say that the process falls within the scope of the provision.

In summary, certain personal aspects should be read as an assessment of the person's personality. There should be drawn a line between personal data that only tells us something objective about a person, and the data that say something more about the character and behavior of the data subject. The criterion will in the following be referred to as the profiling condition.

The second component of the condition is that the evaluation of the person's profile or personality was the intention of the automated processing. The wording of intention implies that the decision maker must have wished to profile the data subject. The addition of this condition

Strictly speaking, the decision maker could circumvent the provision by just stating that the primary goal of the analysis was not to evaluate someone's personality. Taking online advertisement companies as an example, one could argue that the purpose of online tracking and analysis is not just to assess people's personalities but also to give these individuals offers of goods and services. Savin notes this possibility, arguing that the criterion of intention should not form a part of the provision or its assessment:

\footnotetext{
94 Ibid pp. 49-50.

95 Article 8 (1) DPD.
} 
"The key to application of the Article is the intention understood as the data processor's awareness of and desire to analyse personal information. If personal information analysis is not the intended but ancillary effect, the Article would not apply. [...] This is not an ideal solution. It is submitted here that intention should not form part of the provision. The individual should be able to object to automatic decision making based on personal data whether the data controller's intention had originally been to analyse such data or not." $" 96$

However, to mend this unfortunate interpretation of "intention," one could regard most automated decisions as based on several automated processes. For example, one algorithm could calculate the chances of the person being a sports fan, and another algorithm could calculate the price offered for sports equipment. It is enough that one, but not all, of these processes, has the intention of profiling the data subject. If that is the case, the Article will not be inoperable.

The problem Savin raises is also partly a matter of being able to prove that the decision maker wanted to profile the target for the decision. It can in this regard be argued that as long one of the processes inherently involves profiling it must be presumed that such profiling was the intention of the decision maker. Thus, the decision maker cannot escape Article 15 by simply arguing they did not intend to evaluate the personality of a person.

The criterion of "intention" also indicates that the Article will encompass cases where the decision maker has attempted to profile the data subject, but without results. This means that a person has the right not to be subjected to an automated decision even though there was not a profile as a basis for the decision. It is sufficient that the decision maker tried constructing a profile of the data subject.

Moreover, this indicates that Article 15 does not concern itself with whether the attempted profile was 'correct', in the sense that the decision maker actually did not accomplish describing his personality. The data subjects shall also be protected from such attempts. How correct the profile is can, however, have implications for the third condition of significant consequences (2.6.2).

In summary, the first condition of Article 15 is that a profile of the data subject must have been mapped out or tried constructed by computerized means. In the assessment of what con-

96 Savin (2014) p. 4. 
stitutes a profile, one should look at both the data input and the information output. It is not necessary that a profile actually has been built, as long as the computer tried to assess the personality of the data subject. A credit company that measures the creditworthiness of a customer's behavior based on how they use an online shop is an automated process that falls within this condition. ${ }^{97}$

\subsection{Condition 2: A decision based on profiling}

\subsubsection{Automated individual decisions}

The second condition is that a "decision" must be "solely" based on the profiling. The next subsections cover two questions, first how "solely" should be interpreted (2.5.2), and secondly, I look at the limits of human involvement in the decision-making (2.5.3). This subsection explores the three fundamental terms for the second condition, namely what is meant by decision, then whether the decision making has to be automated, and lastly what individual decisions means.

A decision must by definition be a choice between at least two possible results. It is hard to characterize machine-based results as a choice, as these processes are mostly deterministic. ${ }^{98}$ Bygrave has also described the linguistic problem in this condition:

"[...] it could be argued that the term "decision" ordinarily connotes a mental action (the adoption of a particular opinion or belief.)" $" 99$

Yet, we cannot interpret the condition by its linguistic meaning alone. A teleological approach points to at least two elements that characterize a decision: if the message given to the data subject is of purely informative value and if the message appears to be concluding something. ${ }^{100}$ Examples of decisions include getting a loan from a bank, getting a residential permit to a country, or getting a job offer. These are results that conclude an application made by the data subject. The decision does not need to have a negative effect on the data subject; an approval of a loan application also lies within the wording of the provision.

97 The Swedish company Klarna is for example a company that uses the data extracted from the data subject's use of a website, e.g. cdon.com, to decide the creditworthiness of the person. If the customer is doing the trade in the middle of the night, it is reason to think that it is an impulse purchase. See Gustafsson (2014) and Grundberg (2014). I will return to activities such as this in chapter 4 (application of Article 15).

98 There are on the other hand ways of using nondeterministic algorithms in data mining. See Anrig (2010) pp. 76-79.

99 Bygrave (2002) p. 321

100 This is also illustrated by a recommendation from the Danish Data Protection Authority: "Den omstændighet, at der f.eks. udsendes material af oplysende karakter til en række personer, der star opført på en edbliste, vil ikke udgøre en afgørelse i bestemmelsesns forstand.” see VEJ nr. 126 (2000). 
It is somewhat harder to describe an individualized web commercial as a decision, but it can still be said that a computer somewhere has made the decision to give the specific user a particular commercial. However, an automated request to fill out forms for the application for a bank loan is not a decision, as it does not decide anything for the data subject. One can also argue that such a request only has purely informative purposes.

Furthermore, it can be argued that it is not necessary to clearly define the concept of decision, as Article 15 requires that it needs to involve legal or significant consequences for the data subject. If a message from a computer to a human does not involve either legal implications or significantly affects the person, it will be of little use to know whether it was a decision or not. And if a message to a person actually has legal consequences or is sufficiently important, then it is hard to imagine that the machine-based result is not deciding something for that person.

Another question is whether making no decision at all also is a decision. It is clear that the refusal of getting a higher limit of credit on a MasterCard is a decision. But a different question is, to what degree the Article is applicable to the inaction of a machine. An example is if a mobile phone company gives customer $\mathrm{A}$, but not customer $\mathrm{B}$, an offer of a new phone, because their evaluation of customer B shows that his creditworthiness is not high enough. In its literary sense an omission of taking action is also a choice, which we may interpret as a decision.

However, such inaction does not appear to conclude something, which is one of the characteristics of a decision. To give Article 15 applicability to such cases is nor in accordance with the rationale, which is to prevent decisions that have had an effect on the individual. The implication of this interpretation would also mean that the data subject would always have the right to force companies to consider contracting with him. Hence, the conclusion must be that the omission of making a decision falls outside the scope of the provision.

As previously discussed in 2.4, the basis for the decision - the profiling - needs to be automated. It is important to clarify that the text in Article 15 does not explicitly say that the decision also requires automation. ${ }^{101}$ Yet, if we do not read the condition in this way, it would mean that the application of the provision would not depend on whether a person or computer reached the decision. However, Article 15(1) states that the decision must be based "solely"

101 Nor does "automated" appear in relation to the word decision in the Spanish, Danish, French or Swedish translation. 
on an automated process. As the process of the data subject's personal aspects has to be automated, so must the decision making be automated. ${ }^{102}$

Lastly, the use of the term "individual decision" has to be addressed. The word "individual" appears only in the title of the provision and not in its text. A contextual interpretation of this term could indicate a demarcation of the provision to decisions that only applies to one person at a time. ${ }^{103}$ If the same decision applies to more than one person at a time, it would consequently fall outside the scope of the Article. An example of the latter would be a decision to reach all Norwegian women ages forty to fifty with a particular web commercial. This would entail a quantitative demarcation of the provision.

However, one could also interpret the term as simply meaning decisions made about individuals. Individual appears in most of the translations of the Directive. ${ }^{104}$ To give the provision best possible effect, this interpretation should be laid down. ${ }^{105}$ This interpretation is also in accordance with the rationale behind the Article, as the data subjects should have the right to not be subject to decisions even though other individuals also are subject to the same decision. Automated decisions will in many cases have the same content, e.g., Internet marketing, and it would be easy to circumvent the provision by relying on the first interpretation, stating that more than one person was affected by it.

In summary, the decision condition is abstract but encompasses automated, machine-based results concerning a specific person if they decide something for that person and are not purely informative. The condition will, for instance, cover the previous example of targeting Norwegian women ages forty to fifty with a particular web commercial.

\subsubsection{How the criterion of 'solely' should not be interpreted}

The term "based solely" is what binds the previous two conditions of decision and automated processing together (figure 1). In the previous subsection, the criterion of based solely was interpreted as to mean that the decision making has to be automated, as well as the processing that leads to it.

\footnotetext{
102 That the decision cannot be done by a human being is also supported by the Commissions commentary to the amended proposal, a proposal that had the same wording here as the present Article. COM 422 (1992) p. 26.

103 Contextualized interpretation has relevance according to CJEU case law e.g. CILFIT (20) and Fredriksen (2012) p. 199.

104 Not in the Swedish translation.

105 The principle of effet utile from C-402/07 and C-432/07 (recital 47). See subsection 1.3.
} 
However, based solely can also be interpreted as requiring that the decision is made purely on the basis of profiling. Put in a different manner; it is clear that the decision has to be based on profiling, but does this exclude decisions that also takes other types of data into consideration?

This interpretation should be rejected, as it could render the provision impractical since automated decisions always take other kinds of data into account. Ad companies will for example, not be satisfied knowing that a potential customer is within their target group, as they also need to know what goods they have in stock and what price they can offer it at. The latter types of data are of a more objective character and will be the same for every person the ad company targets.

The purpose of the Article is to give data subjects a right not to be subject to decisions when their profiled data forms the basis of a decision. It should then not matter if other, more objective data also is part of the decision basis. Thus, the term "solely" should therefore only serve as a reminder that the decision needs to be automated.

A potential problem with the above-mentioned interpretation is that decisions only partially based on profiling fall within the scope of the Article. However, this possibility will likely not cause any practical concern in the application of the provision, because once such a decision meets the requirement of either having legal or significant consequences it falls within the purpose of the provision to give the data subject the right as prescribed by the Article. ${ }^{106}$

\subsubsection{The limits of human involvement in decision-making}

As concluded in the previous subsections, both the processing and the decision need to be automated to fall within the scope of the Article. Looked at from another angle, if a private company does not want to be subjected to the Article, all they need to do is have a person to review the decisions the computer makes. This subsection examines how much human involvement is necessary for the decision-making process to no longer be encompassed by Article 15.

106 A different solution could be to interpret the condition of automated decision restrictively. A decision could be understood as every processing operation that is ended before the final result reaches the data subject. For instance, could the analyses of the data subject's transactional history be seen as leading to a decision, before it is paired with more objectively data for the final main decision, like the current market risks and so on. As long as one of these sub-decisions were purely based on a profile, the final decision would fall within Article 15. This is on the other hand a more complicated view of the provision than reading "solely" restrictively, where the problem actually arises. 
Thus, the question has as a prerequisite that the decision has not yet been made. However, logically, the level of human involvement that is necessary for the decision to no longer be considered fully automated must be the same standard that is required in the exercise of the right under Article 15 after the decision has been made (subsection 2.2). The decision must be considered to have been made at the time the legal or significant consequences takes effect (even though the data subject has not been informed of it). ${ }^{107}$

First, one could argue that it is impossible to have a fully automated decision without any human involvement. Theoretically, at some point in time, a person must have decided either to write the program that makes the automated decision or to build the machine itself. However, one should not take this fact into account when exploring the Article, as it would render the provision inoperable. We must draw a line somewhere for how much human interference is necessary before the data subject does not have the right under the provision.

There is reason to treat the simplest human involvement the same way as automated decisions. It would be easy to circumvent the Article if a bank only had to employ a person to click "okay" for every automated response the computer had made when processing requests for loans or increases in credit levels. Hildebrandt points out this potential circumvention:

"The most simple form of automated profiling is when profiles are generated and applied in the process of data mining, after which human experts sit down to filter the results before making decisions. In this case we have no autonomic machine behavior, because decisions are taken by human intervention. It may, however, be the case that these decisions routinely follow the machine's 'advice,' bringing the whole process very close to autonomic machine profiling." 108

Based on a teleological approach to the interpretation of the provision, one could argue that the goal is to have genuine human involvement in the decision making. If a person monitors the whole process, as Hildebrandt describes, it has exactly the same outcome as an automated machine profiling. The rationale behind the provision - the fear of not fully trusting the computer alone - also supports the requirement or the possibility of genuine human involvement. This also requires that the person involved in the process has the ability to change the out-

107 Another solution would be to say a decision is reached at the time the computer has finalized its result. However, to make it practically possible for companies to comply with the provision, namely involving human thought, it should not be considered to be a decision before the consequences takes effect.

108 Hildebrandt (2008) p. 28. 
come of the decision. ${ }^{109}$ The preparatory works to the Norwegian transposition of the Directive also illustrate this interpretation (my translation):

The decision must secondly be solely based on an automated process. This means that the decision-making process can only take place in a computer system. If one or several people take part in the decision making, as for example by interpreting the results of the automated processing, then the condition will not be fulfilled. The manual part of the processing must, however, be real and embodied in a mandate or practice. ${ }^{110}$

The Commission was concerned about the "strict application by the user of the results produced by the system." 111 Thus, the answer to this question is that it does not require much human involvement before the decision is not entirely automated. But the person involved in the decision making should at least have the possibility to change or modify the results of the machine.

\subsection{Condition 3: The decision must be significant or cause legal effects}

\subsubsection{Alternative 1: Decisions producing legal effects}

The third and last condition is that the decision must either have had legal or significant consequences for the data subject. The following conditions are alternative, meaning that a situation requires only one of them for the Article to be applicable.

These conditions were not part of the first proposal from the Commission, but were added in the amended proposal. ${ }^{112}$ The Commission noted that the initial proposal was rewritten in order "more closely to define the limited cases" in which the provision was to apply. ${ }^{113}$ The conditions of "significant" and "legal" consequences do for that reason have the purpose of limiting the scope of the provision to scenarios where it is important to have the right.

Decisions that have legal consequences will presumably be based on legal grounds. ${ }^{114}$ These are decisions that give an individual certain obligations to do or withstand something, or deci-

\footnotetext{
109 Öman (2011) p. 428.

110 NOU 1997:19 p. 151.

111 COM 422 (1992) p. 26.

$112 \operatorname{COM}(92) 422$ final - SYN 287

113 COM 422 (1992) p. 26.

114 I presume that most Member States to the EU has some sort of principle of legality that demands legal grounds for decisions made by administrative organs and Courts, when they make decisions that has consequences for private citizens. For Norway's part see for examples Boe (2010) pp. 234-237. The principle does not apply to decisions by private companies, but it is hard to think of a scenario where a private entity sin-
} 
sions that give the subject a right. In other words, the national courts must be able to enforce the decision. ${ }^{115}$ However, the legal implications do not have to be significant.

An example that clearly has legal effects is if a data subject loses his right to unemployment benefits on the basis of a statistical model that shows that the individual probably is committing fraud. ${ }^{116}$ All court and administrative decisions will also fall within the provision as long as they are based on legal grounds. ${ }^{117}$

The criterion "legal effects" has probably more importance for administrative decisions and governmental affairs than it has for the decisions made by private businesses, as private entities cannot singlehandedly enforce obligations or give rights to individuals without consent. Yet, some actions made by private companies in relation to contractual obligations may be identified as legal consequences. However, one of the exceptions to the right under Article 15 is if the decision is made in the "course of the entering into or performance of a contract," which means that this alternative may be of little practical effect for private companies. ${ }^{118}$

\subsubsection{Alternative 2: Decisions significantly affecting a person}

The wording of significantly affects indicates that the assessment should be the consequences the decision may have. Beyond this, the wording of significant does not provide much guidance, and this condition is best suited for concrete assessments. I will still outline some potential limitations of the condition.

The amended proposal of the Directive uses the term "adverse decision" instead of "significantly affects" him. ${ }^{119}$ The word adverse has a more negative connotation than significantly. Thus, the previous proposal had as a prerequisite that the decision would affect the data subject in a negative manner, while the wording "significantly" also covers decisions perceived as positive. Some decisions may have both positive and negative consequences, as for example, when a person gets a higher credit limit from a bank but not as high as he requested. The current provision covers these decisions, though they do not necessarily have adverse effects.

gle-handedly makes a decision with legal consequences without a prior request from the subject to the decision, e.g. breach of contract.

115 This is without prejudice to the individual legal orders in the Member States, where different procedures for invoking legal rights and obligations may exist.

116 BigInsight is currently developing such models, see footnote 61.

117 This is a safe conclusion as Article 15 is based on French legislation that prohibits automated court decisions based on profiles.

118 Article 15 (2) a. There are some other conditions that also must be met if this exception is to be used, so there still might be some practical effect of this exception, but it is clear that it still have more importance for the administrative decisions.

119 COM(92) 422 final - SYN 287 
Some types of decisions are arguably more significant in general than others, such as decisions with economic consequences. The denial of an application for a loan or credit increase could mean that the person cannot afford something. This is supported by the mentioning of "creditworthiness" in the Article. The same argument can be made for other types of decisions that are based on the profiling the Article itself mentions, such as performance at work. If for instance, a raise in salary is calculated by a machine alone it could be significant. The more money that is at stake, the more reason there is to see the decisions as significant.

Secondly, it is relevant whether a computer typically makes the particular type of decision or if a human normally does it. For example, the core of the provision speaks more to the right to contest decisions of administrative matters, like public and welfare benefits, than the right to oppose individualized Internet commercials. The more important it is to have a person oversee the decision and the process leading up to it, the easier it would be to call the decision significant.

Some decisions may have emotional or social consequences, and there is nothing in the wording of the provision that excludes these decisions from Article 15's scope. This also has some support in legal literature:

“There is no further definition of a 'significant effect,' though it is very unlikely this would be limited to decisions having a pecuniary effect." 120

It is nevertheless harder to claim that a decision is significant because it has social or emotional consequences than it is to argue that a decision is significant because of its economic effects, as there is less objective evidence for the former.

A more uncertain argument is whether the data basis for the decision can influence whether it considered being significant. In other words, can sensitive data render the effect more or less significant, even though the computer could have reached the same result with nonsensitive data?

Decisions based on the data subject's sex life will certainly feel more unpleasant than decisions based on more objective data. ${ }^{121}$ However, the wording of affects may undercut the rel-

120 Büllesbach (2010) p. 74.

121 Tinder, a dating application, has an algorithm that calculates the desirability of the user, based among other things on how many people wants to meet the user for a date. See Braseth (2016). This can in turn be used as a profiled basis for different ads, as for example beauty products, dating courses and so on. 
evance of this argument. In this view, the provision would concern the degree to which the decision disturbs the data subject, not the significance of the decision itself. For instance, a refusal of a bank loan on the basis of a profile of the data subject might seem like an important decision in itself, but the degree to which this refusal impacts the data subject requires an evaluation of consequences.

However, in accordance with the rationale behind the Article, namely concern about the continuing growth of profiling, it would be fair to consider how extensive the basis for the decision was and the data in the profile. This is not strictly in line with a textual interpretation of the provision but results from a teleological approach.

\subsection{The subject of Article $\mathbf{1 5}$ and the entity accountable}

The wording of Article 15(1) does not explicitly use the term "data subject" but instead uses "every person." One could interpret the latter term in such a way that the provision provides protection to people that have been targeted by the decision, even though they are not identifiable and are thus not data subjects. According to Schreurs, the provision does not limit itself to profiled persons, as the Article does not specify "that this must be an automated processing of his or her personal data.",122

However, the Article 15(1) also says the decisions need to affect him, and it must be based on an automated processing with the intention of evaluating personal aspects relating to him. Although the wording is not data subject, it is safe to assume that only data subject will have rights under the provision. This is also supported by the wording of Article 15(2) which consistently uses the term data subject. Thus, Öman, in the Swedish commentary to the Swedish Personal Data Act, writes (my translation):

The question of who can submit a request is addressed in the commentary to $\S 3$ in relation to the definition of the data subject. ${ }^{123}$

The Article does not explicitly mention who is responsible for complying with the right of not being subjected to automated decisions. However, it must for all practical purposes be the decision maker. This can be the data controller but also the data processor if the controller has delegated the task of making the decisions to another entity.

122 Schreurs (2008) p. 254.

123 Öman (2011) 427-428. 
The provision consists of several ambiguous terms and abstract concepts; however, we can summarize it as having the following scope: an automated processing that seeks to profile the data subject must be the basis for an automated decision that targets the data subject specifically with legal or significant effects. In the assessment of what is significant one needs to examine the consequences in a narrow sense, which is not limited to the pecuniary effects, and secondly the complexity and the nature of the profiled basis.

The first main question of this thesis, as previously mentioned, asks under what circumstances these conditions are fulfilled, and the right of human re-examination can be applied. Chapter 4 will cover this question after an examination of the exceptions in Article 15(2) in the next chapter. 


\section{$3 \quad$ Article 15(2) of the DPD}

\subsection{Introduction}

Article 15(2) provides two exceptions to Article 15(1), namely (1) when the automated decision is taken in the course of entering into or fulfilling a contract (contractual exception), or (2) when a Member State law authorizes the decision:

2. Subject to the other Articles of this Directive, Member States shall provide that a person may be subjected to a decision of the kind referred to in paragraph 1 if that decision:

(a) is taken in the course of the entering into or performance of a contract, provided the request for the entering into or the performance of the contract, lodged by the data subject, has been satisfied or that there are suitable measures to safeguard his legitimate interests, such as arrangements allowing him to put his point of view; or

(b) is authorized by a law which also lays down measures to safeguard the data subject's legitimate interests.

This chapter will not dwell on the second exception because this requires an assessment of the Member States laws, and there is a considerable variation in how the provision has been implemented. ${ }^{124}$ The following chapter is divided into three subsections, all dealing with the contractual exception in Article 15(2) (a). The first subsection assesses what is meant by the condition of entering into or performance of a contract (3.2).

In addition to there being a contractual relationship between the decision maker and the data subject, one of two alternative conditions has to be fulfilled. Either the request from the data subject to enter into the contract must have been satisfied (3.3.1), or the data controller must have put into place measures to safeguard the legitimate interests of the data subject (3.3.2). Lastly, I examine whether the data subject must have been the party to request the contract in the situations where the decision maker makes use of the alternative condition of safeguards (3.3.3.)

\subsection{Condition 1: Entering into or performance of a contract}

The rationale behind this exception is that a contract establishes a relationship of confidence between the decision maker and the data subject. ${ }^{125}$ Thus, the data subject does not need to

124 Korff (2002) pp. 112-116.

125 The preparatory works states that it must have been a "relationship of confidence", between the data subject and the controller, when "approaching the state of a contract". See COM 422 (1992) p. 27. 
have the right of human involvement, as his interests are safeguarded either through the satisfaction of his contractual requests or through other suitable measures implemented by the data controller.

The contractual exception applies in two cases, one being the pre-contractual phase, when the data subject is entering into a contract with the decision-maker, and the second being the stage during which the parties fulfill the contractual obligations. This means that if someone is simply browsing a website, which would profile him and make decisions about him, does not fall within the scope of the exceptions. The website must at least have prompted the person for a contractual conclusion.

The terms "course" and "exercise" mark the time the data controller has the opportunity to make an automated decision for the data subject. However, the wording also bears the connotation that the decision must have had some actual relation to the content of the contract. The decision cannot be exempted just because it happened in the span of time before the parties entered into a possible contract. An example is if a company makes a prediction of the customer's creditworthiness in an online shop, and based on those predictions the company gives the person payment deferral. ${ }^{126}$ However, if the company at the same time uses that profile to make a decision not connected with the contract, such as showing that person an ad, then it would not be a decision done in the course of entering into a contract, even though it happens in the same span of time (the pre-contractual phase). ${ }^{127}$

The wording "in the course" and "performance of a contract" also suggests that the automated decision cannot be exempted after the contract has ended. This means, for example, that an online newspaper cannot continue to display personalized ads after the data subject has ended his subscription with the paper.

Some of the questions the contractual exception raises cannot be answered through an interpretation of the Article alone, such as what constitutes a contract and at what point a contract is considered entered into. The answers to these questions must follow the Member States national legislation relating to contracts and contract signing. There is a divide between the contractual laws in common law countries (UK and Ireland), civil law, and the legal tradition in Scandinavian countries. ${ }^{128}$

\footnotetext{
126 Like the previous examples of the Swedish company Klarna (footnote 97). This case will be expanded on in the next chapter, concerning the practical application of the provision.

127 In addition the company would need a specific consent for this decision and do it within the purpose limitation principle (subsection 1.5).

128 For differences between civil and common law see Bygrave (2015a) pp. 19-20.
} 
However, the differences in national legislation have become less significant, with the increasing standardization of contract on the Internet. These are also the contracts that are practical in relation to Article 15, as many automated decisions happen via online services. A problem with these contracts is that they are often compulsory for using a website or a service. Custers explains this problem:

"[...] these inquiries is often mandatory in order to obtain a product, service, or price reduction, a take-it-or-leave-it situation is created, in which there is often no choice for a consumer but to fill in his personal data." 129

However, as long as the national legislation accepts terms and conditions as contracts, they will fall within the condition of contract under Article 15(2). EU law has not legislated this issue aside from when a contract becomes too unreasonable in consumer law. ${ }^{130}$ There is, on the other hand, no legislation that permits a consumer to get a service or product without accepting the contract a service provider offers. ${ }^{131}$

\subsection{Condition 2: Satisfaction or safeguards}

\subsubsection{Alternative 1: The condition of satisfaction}

In addition to a contractual relationship with the data subject, the decision maker needs to fulfill one of two alternative conditions. Here I will examine the first alternative, namely that the decision maker must have satisfied the request lodged by the data subject to enter into or performance of a contract.

The word "satisfied" indicates that the data subject's requests must have been fulfilled. Either the data subject must have obtained a contractual binding with the decision maker (if the automated decision happened in the course of the contractual relationship) or the data subject's contractual rights under the performance of the contract must have been satisfied. However, the parties to a contract must always 'satisfy' their contractual obligations for not causing a breach of contract, so the criterion of performance is not treated any further in this chapter. Thus, the following examination concerns the pre-contractual phase.

The wording does not specify if all the requests of the data subject must have been satisfied. For example, a customer might receive a loan but with a higher interest rate than the data

129 Custers (2004) p. 18 and Bygrave (2015a) pp. 40.41.

130 E.g. Article 3 to Directive on Unfair Terms in Consumer Contracts 93/13 (1993).

131 Interestingly, the new GDPR, to some degree regulates conditional consent in Article 7(4). This is examined in subsection 6.5. 
subject asked for. If the only requirement is that the data subject must have obtained a contract with the decision maker (not the more detailed terms and conditions the data subject might request), then the exception encompasses the previous example.

Under the amended proposal from the Commission, "any" request by the data subject had to have been satisfied. ${ }^{132}$ This wording suggests that all requests of the data subject, even the more detailed ones concerning the interest rate in the example above, must be met for the exception to apply. The weight of this argument is, on the other hand, limited, as the Council amended the proposed text and because the preparatory works, in general, is of little significance. ${ }^{133}$ At the same time, there is no indication that the Council meant to change the scope of the exception.

To give the right in Article 15(1) best possible effect, the exception should be interpreted in light of the provisions aim, namely not to be subjected to significant decisions. A contract with the decision maker does not preclude the significance of the decision. If for instance, the data subject is granted a loan but at a much higher interest, because he lives in a poor neighborhood, one could claim that such a decision is significant.

There is little reason to exempt a bank from the provision merely because they gave a person a contract. Thus, the conclusion is that the data subject should retain the right under Article 15(1) even though he has been offered a contract, on the premise that the decision still is of such importance that it falls within the first paragraph.

\subsubsection{Alternative 2: The condition of safeguards}

The decision maker has the opportunity to implement suitable measures instead of meeting the data subject's requests when entering or fulfilling the contract. This chapter raises two questions: (1) what is meant by legitimate interest and suitable measures, and (2) is it also a requirement under this alternative condition that the request to enter into the contract has been lodged by the data subject (3.3.3)?

This alternative condition consists of two components. First the legitimate interest of the data subject must be identified, and secondly the decision maker must implement suitable measures that safeguard the interests.

132 C 311/04 (1992)

133 95/C 93/01 (1995) 
The interests of the data subject should be interpreted as the rights and freedoms as protected by the Directive. Since the interests must be legitimate, they are relative in nature. Beyond this, the wording does not provide much guidance. However, a contextual interpretation indicates that the interests protected under Article 15(1) must be believed to be legitimate.

One of the purposes of the provision is to prevent companies from only having computers analyze the data subject in important matters, as examined in subsection 2.3. Hence, the interest of being judged by a human being or having some insight and ability to contest this issue is legitimate. Nothing in the preamble nor in preparatory works gives any indication of other legitimate interests that could make an exception to the automated decisions. They commentary from the Commission only states that the "Member States are free to clarify" both what is meant by legitimate interests and what suitable measures should be put in place. ${ }^{134}$

Turning to the second component, appropriate measures, Article 15(2) does itself prescribe that there should be "arrangements allowing him to put his point of view" forward. In relation to the interest mentioned above, some arrangements that allow the data subject to ask for human involvement would also be suitable measures that safeguard him. ${ }^{135}$ One should not, however, interpreted this as a right to demand human involvement. Such a safeguard under this exception would render a contract with the data subject redundant, as it would give him the same right as afforded under Article 15(1) (on the premise that the provision not is transposed as a prohibition). ${ }^{136}$

It would also be expected for other principles of European data protection law to serve as suitable safeguards, such as the data minimization principle and measures to anonymize or at least pseudonymize the data in the profiling process. The data minimization principle stipulates that the decision maker should limit the collection of personal data to what is strictly necessary to make the decision. ${ }^{137}$ Pseudonymization is when other values replace personal data in order to render the identification of the data subject difficult. It is still possible to identify the individual through the use of additional information, as opposed to anonymization, in which the identification is no longer possible without reasonable means. ${ }^{138}$

\footnotetext{
134 COM 442 (1992) p. 27.

135 Borgesius (2015) p. 378.

136 Article 22 (3) to the GDPR gives the data subject a right to always obtain human involvement, and this will be further examined in chapter 6.

137 Colonna (2013) p. 1.

138 The line between anonymized and pseudonomized data can be difficult to draw, but is summarized in WP216 p. 3 and 10. Pseudonymisation has also been defined in Article 4(5) GDPR.
} 
Furthermore, the wording of suitable indicates that what is demanded of safeguards is relative, and its assessment should rest on the character of the decision, the profile that lies as a basis for it, and the relative strength between the data subject and the decision maker. In other words, a principle of proportionality should guide this assessment. The rationale behind the contractual exception, as mentioned in the introduction, is that a contract creates a relationship of confidence between the data controller and the data subject. The preparatory works illustrates this principle:

"[...] if the two sides are not on equal terms (which is the case with a job-seeker, for example) neither consent nor the hope of a contract provide a sufficient safeguard. Under paragraph 2 a data subject may be required to accept a decision of the kind referred to in paragraph 1 if the decision is taken under a contract between the data subject and the controller, or in the course of the conclusion of such a contract, on condition that the data subject's request is met, or that there are appropriate measures to safeguard his legitimate interests $[\ldots]^{, 139}$

This means that banks and insurance companies must put in place safeguards that offer a higher level of protection than service providers that display individualized ads and commercials. This is because the inequality between a bank and an individual is greater than between the same person and a website, and because a bank's automated decision presumably has greater significance for the data subject.

\subsubsection{A request lodged by the data subject}

It is clear that the data subject must have been the party to seek the contract if the decision is exempted through the first alternative (satisfaction of the request). The question here is if the data subject must have been the one to request the contract also for the second alternative of safeguards.

The outcome of this interpretation is of practical importance, as it clarifies the scope of the contractual exception. Individualized online marketing, for example, that offers a product to which the data subject subsequently accepts, will form a contract that the is requested by the data subject. Similarly, the ads for consumer loans or insurance, which has become quite common, will not be exempted if the data subject is rejected such service, even though the company has put in place safeguards. Article 15(2) (a) stipulates:

139 COM 442 (1992) p. 27. 
"[...] request for the entering into or the performance of the contract, lodged by the data subject, has been satisfied or that there are suitable measures to safeguard his legitimate interests $[\ldots] "$

The wording of "or that there are suitable measures" is equivocal. Nor does a comparison with other language version does provide much guidance. ${ }^{140}$ As stated in the introduction, it is clear that the data subject must have been the one to request the contract under the first alternative (satisfaction). But that the data subject must have been the party to request the contract can already be said to follow from a wording of satisfaction, as this duty lies on the decision maker. To give the criterion "lodged by the data subject" independent meaning, it should be interpreted as to apply for the second alternative condition (safeguards). Previous versions of the Article did not include the criterion "lodged" by the data subject. ${ }^{141}$ Thus, it can be argued that it was added to clarify that it applies to both alternative conditions.

This understanding of the exception might lead to arbitrary consequences, as a person going to an online shop and requesting a product or a service might not retain his right under Article 15 , while a person that clicks on an ad for the very same product or service will keep the right under the provision. It can, on the other hand, be argued that there is more reason to protect the persons who have received personalized offers than the persons who themselves seek out a contractual relationship with the data controller. This is also best in line with the rationale behind the contractual exception. ${ }^{142}$ Thus, the conclusion is that the data subject must always have been the one to request the contract, for the decision to fall within the scope of the contractual exception.

In summary, the exception under Article 15(2)(a) is not as broad as it first appears from its wording. It is not sufficient that the data subject has entered into or will enter into a contract with the decision maker. In addition, the decision maker must either have satisfied the requests by the data subject, or must have put in place measures to safeguard his interests. For both alternative conditions, the data subject must have been the party to have requested the contract.

140 The wording of the Danish and the Swedish versions suggests that the criterion of "lodged by" the data subject only applies to condition of satisfaction, whilst the French version looks more like the English text.

141 COM 422 (1992) p. 91.

142 See subsection 3.1. 


\section{The practical application of Article 15}

\subsection{Introduction}

This chapter examines the limits of Article 15 through the six examples introduced in subsection 1.2. The first four examples are connected with online scoring techniques, namely credit scoring in online banking systems, credit scoring in online shops for the purpose of payment deferral, the automated evaluation of insurance terms, and e-recruiting.

The fifth example is the practice of weblining. By weblining I mean price differentiation, e.g., in an online shop, but also search differentiation in which a company offers person A and person B different products or services even though they used the same keywords. The last example is closely related to weblining, namely online behavioral advertising (OBA). This is when a person receives customized advertisements on the Internet based on his or her profile.

The examples are not "cases" in the sense that they represent single episodes that have happened. However, these examples are founded on research and statements from the industry. The next subsection (4.2) will give a short explanation of online scoring. The subsequent subsection (4.3) will discuss how OBA and weblining work before an examination of the limits of Article 15(1) in (4.4). Lastly, I will examine the application of the contractual exception (4.5).

\subsection{Online credit scoring}

Credit scoring can be described as a numerical representation of the creditworthiness of a person, which predicts the likelihood of whether that person will pay a debt or not. ${ }^{143}$ Several services are increasingly relying on automated scoring techniques, as they are more costeffective compared to employing personnel. Automated scoring can arguably provide more consistency and possibly accuracy in the decision making compared to a manual evaluation. ${ }^{144}$

Seemingly, some online banks use automated scoring in the initial application for a loan. ${ }^{145}$ If the computer decides that the person is not eligible for the requested loan, he can get an automated refusal. However, if the applicant shows a good credit score, then an employee of the bank will usually take over the application and double check the basic information, such as whether the applicant has typed in the correct personal information. This is a natural prioritizing of human resources, as it is more important for a bank to scrutinize the applicants with

143 Oxford dictionaries (2016).

144 Thomas (2002) p. 5.

145 This is at least how Norwegian Bank conduct their credit scoring. This information is based on a conversation with their customer support, $19^{\text {th }}$ April 2016. 
good credit scores to minimize the risk of lending out money than to use resources on persons which initially appears to have a bad score.

Most of Member States likely have legislation concerning credit scoring, which in some circumstances will overlap with the application of Article 15. By way of illustration, the Norwegian Act on Financial Contracts regulates the duty a lender has to conduct credit scoring prior to granting a loan. ${ }^{146}$ However, as new credit scoring techniques are departing the traditional ways of evaluating the creditworthiness of a customer, it can be questioned whether current legislation encompasses all online activities. ${ }^{147}$ Klarna, which is a credit lender, is known for not basing their credit ratings on formal credit checks, as the customer's behavior can give them a more accurate view of the person's creditworthiness ${ }^{148}$ :

"To avoid losses, Klarna uses an algorithm with over 200 variables measuring client risk. They include previous purchases, the time of the day the customer buys goods, the frequency of purchases and even how shoppers type their names."149

The same kind of technology can now aid business for employment purposes, through the automated prescreening of applicants called e-recruiting. ${ }^{150}$ This is strictly speaking not credit scoring, but it works it the same way, as it gives applicants a score based on their past experiences and personality traits. Research shows that automated prescreening can perform on par with human recruiters. ${ }^{151}$ The research on e-recruiting was based on extracted data from the applicants' LinkedIn profiles and subsequently ranked the applicants, which allowed human resources to interview the top candidates and generate automated rejections for the others. ${ }^{152}$

Similar to the above-mentioned examples, scoring techniques can also calculate insurance underwriting. This is the evaluation of the risks in insuring a particular person and their assets and uses the same information to set the price for the insurance policy. ${ }^{153}$ Insurance compa-

146 E.g. the Norwegian Financial Contracts Act Section 46b.

147 The Norwegian Financial Contracts Act operates for examples with formal concepts of which entities are considered to be financial insitutions, under section 1 (2).

148 Hildebrandt (2013) p. 15

149 Gustafsson (2014).

150 Faliagka (2012).

151 Faliagka (2012) p. 551. The average error rate by the computer was around $4 \%$ compared to the ranking done by experience recruiters, except for the recruitment of senior positions that require specific qualifications.

152 Faliagka (2012) pp. 554-555 and 566.

153 Yan (2006) p. 2106. 
nies do not yet use automated insurance underwriting to any great extent, but this will likely be more common in the future. ${ }^{154}$

\subsection{Online behavioral advertising (OBA) and weblining}

There are several ways for websites to gain income, like paid subscriptions, but the most popular base for revenue is advertising. ${ }^{155}$ Much online content is free of charge for this reason. Web sites with a desire for revenue will often track their users for the purpose of customizing ads and displaying them on their site. ${ }^{156}$

OBA is a strategy that advertisement networks use to increase the price of online ads. ${ }^{157}$ Commercials shown using OBA techniques have on average a price that is 2.68 times the value of ads not shown using OBA, and this is because the ads have a greater appeal to the user being profiled. ${ }^{158}$

Weblining is here a collective term for price differentiation and search differentiation. Price differentiation is when two individuals get the same product offered at different prices, and search differentiation is when a website steers the individual towards "appropriately priced products" based on the profile of that person. ${ }^{159}$

In its essence, discrimination involves treating comparable cases differently or treating different cases similarly. This thesis uses the term "price differentiation" as opposed to "price discrimination," as discrimination requires causation and not just correlation between the data gathered and what happens to be a price variation or search variation.

Telefonica Research and Development ${ }^{160}$ has proved empirically that price variations occur, but the company has found no evidence that such variations are based on differences in the

\footnotetext{
154 Batty (2009).

155 Stone-Gross (2011) p. 1.

156 HTTP cookies are often used to track users for this purpose, and, according to the Norwegian Data Protection Authority, between one hundred and two hundred of these cookies are placed on the Internet browser when one visits a Norwegian online newspaper. See Datatilsynet (2015) p. 26.

157 Beales (2010) p. 1.

158 Beales (2010) p. 3.The numbers are based on research from 2009.

159 Mikians (2012) p. 1.

160 Telefonica Research and Development is a sub-company of the Spanish Telefonica Group, whom is a broadband and telecommunications provider. The research center has done some of the most extensive research on detecting price discrimination and differentiation online, and their research will be used throughout this chapter.
} 
data subject's personal data. ${ }^{161}$ They have, however, concluded that there is differentiation in search results based on the user's profile. ${ }^{162}$ It is nonetheless a technical possibility:

"It would appear that Google is present on most e-retailers with their analytics (95\%) and doubleclick (65\%) domains. Social networks have also significant presence on the retailers' sites through their widgets: Facebook (80\%), Pinterest (45\%), and Twitter (40\%). While we do not see browsing history leading to price variations, it would be relatively easy for popular third parties to assist in price variations, fueled by the information they collect across the web. We leave this to future work."163

In summary, even though there isn't sufficient evidence proving price discrimination has occurred, except in some minor incidents ${ }^{164}$, it is a phenomenon that is technically possible like OBA. Hence, I include it when discussing the examples in the further assessment of Article 15 .

\subsection{The application of Article 15(1) \\ 4.4.1 Automated decisions based on profiling}

Three conditions require fulfillment before an individual has the right under Article 15. The two first conditions, of (1) automated decision based on (2) profiling, are treated in this subsection.

The operations of online credit scoring, $\mathrm{OBA}^{165}$, and weblining can all be automated. They can also result in decisions towards a person, thus fulfilling the first condition. However, it could be argued that search differentiation is the omission of a decision as the data subject precisely is not shown a certain search result, and thus, not fulfilling the condition. ${ }^{166}$ However, the computer has actually made the decision of showing person A other products or services than that of person $B$. Hence, it should be considered as a decision, though the possible discriminatory consequences lie in what the data subject was not offered.

Moving to the second condition, it is clear that online credit scoring, e-recruiting, and automated insurance underwriting can be types of processes that evaluates certain personal aspects

\footnotetext{
161 Mikians (2012) p. 5 and Mikians (2013) p. 5.

162 Ibid.

163 Mikians (2013) p. 5. See also Narayanan (2013).

164 Price differentiation of E-books on Kindle, see Mikians (2013) p. 5.

165 Datatilsynet (2015) p. 9. By 2016 around $25 \%$ of the Norwegian OBA market will be fully automated, and it has been in rapid growth from 2012.

166 See subsection 2.5.1.
} 
of the data subject. Article 15(1) explicitly mentions "creditworthiness, reliability and conduct" as examples of profiling.

OBA and weblining are also practices that analyze the individual from whom they collect data, and try to fit that person into a category that a corresponding ad or search result can target. Therefore, the second condition is also fulfilled.

The third condition is that the decision either must have legal or significant consequences for the person. I first assess the examples in view of legal effects, but the main discussion will focus on whether the examples can be said to have significant consequences.

\subsubsection{Decisions with legal consequences}

This thesis has previously interpreted "legal effects" as when automated decisions either give a person a right to something or an obligation to withstand something, which typically a court can enforce. ${ }^{167}$ The refusal of a loan, payment deferral, or insurance scheme based on credit scoring, or the rejection of a job application can hardly constitute decisions with legal consequences. It is also difficult to imagine that targeted online decisions have legal effects, especially individualized ads for products or services.

However, the Belgian Data Protection Authority argues that an ad that gives you an offer of a product with a reduced price might constitute a decision with legal consequences. This interpretation was given to Article 20 proposed by the Commission in 2012, but the proposal had the same wording as the current Article 15 on the subject of legal consequences. ${ }^{168}$ Borgesius has also questioned this, but without drawing a conclusion:

"Presumably, the Authority sees a price offer as an invitation to enter an agreement, which could indeed be seen as having a legal effect. This interpretation would make Article 15 applicable to certain types of price discrimination." 169

Whether an ad at all can have legal consequences will presumably vary based on the legal orders in the individual Member States. Under Norwegian law it is, for instance, more fitting to describe ads as offers that will have legally binding effects first when a person accepts it. ${ }^{170}$ The decision to give a price, even a reduced price, might have legal significance down the

\footnotetext{
167 Subsection 2.6.

168 Opinion 35 (2012) p. 20. Article 20 is now Article 22 GDPR.

169 Borgesius (2015) pp. 375-376.

170 Lilleholt (2014) p. 219.
} 
road when the individual accepts the offer, but the decision does not have a legal effect in itself.

The conclusion is that it is the Member States contractual laws that determine what offers that have legal effects. It is also up to the Member States law to decide at what point in a contractual relationship legal effects occur, for example at the offering or when the offer has been accepted.

\subsubsection{Decisions with significant consequences}

The starting point in the assessment of significance must be the consequences the decision has. The preparatory works mention that the refusal of a loan based on a negative credit score is a decision with significant effects. ${ }^{171}$ This is also supported by the fact that "creditworthiness" is mentioned in the Article as an automated process a person should be protected against. Other types of decisions based on scoring techniques, such as those made in erecruiting, online stores, and automated insurance underwriting should, therefore, be treated the same way.

However, it can still be argued that the application of Article 15 requires a case-by-case assessment. The lower limit of significance might be the refusal of a one hundred Euro increase on a credit card, while the request for a mortgage impacts the data subject more profoundly. Other factors are also important, such as the quality of the decision and the data basis, namely the profile of the data subject. This is especially important in e-recruiting practices. I expand on these factors further in regard to weblining and OBA, because these examples do not have direct financial effects.

It is reasonable to say that OBA has no direct significant consequences beyond being a nuisance for the targeted persons. The Commissions commentary to the amended proposal suggests that the effect of commercial brochures won't be significant:

"The person must be subject to an adverse decision. The decision must be one which can be invoked against him, one which has consequences for him; thus, the simple fact of sending a commercial brochure to a list of persons selected by computer is not a decision adversely affecting them for these purposes." 172

171 COM 422 (1992) p. 27.

172 COM 422 (1992) p. 26. 
One could argue that web commercials deserve similar treatment as physical brochures. The decision to show an ad will seldom involve any financial impact on the data subject. In this way, it is easier to argue that weblining can be significant, as price differentiation possibly will result in monetary effects. However, just considering the monetary effects is a too narrow assessment based on the rationale behind the provision. Part of the reason for enacting Article 15 was to combat some of the dangers connected with profiling, as well as the risk in leaning on machine decisions alone. It can also be argued that the possibility of extensive profiling is greater for online advertisement today, than it was for commercial brochures in 1995.

It has been claimed that discrimination is inherent to profiling, as "classification and division" are at the heart of it. ${ }^{173}$ Schermer has also argued that profiling poses the risks of deindividualizing and stereotyping the data subject. ${ }^{174}$ Hence, it should be possible to argue some profiling activities in themselves may significantly affect a person.

However, not all discriminatory weblining or ads will be of significance, so one must also consider as to what degree the decision was "correct" or not. By "correct" I mean what degree of quality the decision has. If it is true that person A's willingness to pay more money for a product is higher than person B's, then it is harder to argue that the decision has had a significant effect. This has to be a contextual assessment in which one also considers what type of service or product the price differentiation affects. And lastly, one needs to take into consideration what data the weblining or ad uses as a basis. If the profile comprises a person's sensitive information, it is easier to argue that the following decision is significant. ${ }^{175}$

A problem with the discrimination argument is that it is difficult to prove, as seen for price differentiation in subsection 4.3. It is presumably even harder to prove whether the decision maker is aware of the discriminatory effects, or if the discrimination is simply hidden in the data. However, outright and direct price discrimination based on ethnic profiles or OBA based on sexual orientation may qualify as significant for a person. The principle of data minimization also supports this procedure, as it will force data controllers and data analysts to make better quality decisions based on non-sensitive data. However, if an ad or weblining is nothing out of the ordinary, it would be hard arguing its significance.

Lastly, Borgesius has put forward the argument that the total effect price discrimination has on society is an argument for its significance, though he leaves the conclusion to case law:

\footnotetext{
173 Schermer (2013) p. 138-140.

174 Ibid

175 Article 8 (1) DPD.
} 
"It could also be argued that one targeted ad should generally be seen as a decision that "significantly affects" somebody in the sense of Article 15 . One could focus less on the effects of one automated decision on the individual, and more on the effects of automated decisions generally on individuals and society. Following that line of reasoning, Article 15 can be triggered because behavioural targeting as a practice has significant effects. In sum, the text of Article 15 seems to suggest that the provision only applies if one specific automated decision significantly affects an individual. The correct interpretation of the provision must come from the courts. But, as noted, so far the provision hasn't been applied much in practice." 176

It is tempting to argue for this solution, as it would make Article 15 a more apt provision to deal with profiling practices that may feel intrusive. But this conclusion does not fit well with either the wording or the purpose of the provision. The rationale behind the provision was to protect persons in individual cases.

The conclusion is, nonetheless, that Article 15(1) may apply to OBA and weblining even though they do not have direct financial consequences the data subject. One should weigh the possible discriminatory effects in the application of the provision and consideration of how complex and intrusive the profiled data can be.

\subsection{The application of Article 15(2)}

The contractual exception is most practical in relation to online scoring practices. An individual will either enter into or perform a contract when applying for a loan, a job, or an insurance scheme. The data subject himself will usually be the one who has requested the decision. OBA and weblining, by contrast, involve decisions made about a person without the individual having requested said decisions. ${ }^{177}$

However, decisions that refuse a contractual binding will not be exempted by Article 15(2). This means that once a person gets a job rejection or a credit refusal, they retain their right to human involvement under Article 15(1). Instead of giving the data subject the right under Article 15(1), the decision maker may otherwise put in place suitable measures to safeguard the data subject's interests. As assessed previously, these safeguards are relative compared to the impact the automated decision has. Decisions that rely on online credit scoring and erecruiting practices should at least involve the possibility of the individual giving the decision

\footnotetext{
176 Borgesius (2015) p. 377.

177 A reservation must be taken for OBA and weblining based on a subscription to a website. If a person for example is a paying reader of an online newspaper, then it will be fairly easy to exempt the automated decisions through terms in the contract under Article 15(2).
} 
maker his or her views, as Article 15(2) states. This will remedy the fact that automated decisions always have a margin of error. ${ }^{178}$

In conclusion, it seems as Article 15 may very well have an impact on how companies conduct credit scoring, automated insurance underwriting, and e-recruitment. If the decisions in the specific cases are considered significant because the data subject is refused a service or a job, the level of protection will often depend on what safeguards the decisions maker needs to put in place. The provision may also apply to weblining and OBA, especially the practices that have direct discriminatory effects. None of the exceptions will encompass these decisions, so the data subject will retain his right to demand human involvement. This may, in turn, lead to less significant weblining and OBA practices, because the cost of personnel in these particular cases might be too high.

178 Schermer (2013) 138-140. 


\section{Section 25 of the Norwegian Personal Data Act \\ $5.1 \quad$ Introduction}

The Norwegian Personal Data Act of 2000 incorporates the DPD. ${ }^{179}$ The Norwegian Act has divided Article 15 of the DPD into several sections, namely sections 21, 22 and 25. The first two sections concern the right to information, whilst section 25 implements what can be said to be the core of Article 15 - the right to human involvement in important automated decisions. It is necessary to look at both section 21 and 22 to fully understand the full scope of section 25 , but the thesis will not examine the data subject's right to information.

The wording of section 25 is as follows:

Any person who is subject to a fully automated decision such as is mentioned in section 22 or to whom the case otherwise directly relates may demand that the decision be reviewed by a physical person.

The right pursuant to the first paragraph shall not apply if the data subject's interests in terms of protection of privacy are adequately safeguarded and the decision is authorized by statute or is related to the performance of a contract. ${ }^{180}$

And section 22 reads:

If a decision has legal or another significant effect for the data subject and is based solely on automated processing of personal data, the data subject who is subject to the decision may demand that the controller give an account of the rules incorporated in the computer software which form the basis for the decision. ${ }^{181}$

Section 22 and 25 put together are fairly similar to Article 15 of the DPD but with one apparent difference, namely the absence of the condition of profiling. The two other conditions that make up Article 15(1) are mentioned (automated decision and legal or significant consequences). ${ }^{182}$ No Norwegian source of law indicates that these two conditions should be

179 See e.g. Johansen (2001) p. 49 for complete historical background.

180 The translation is done by the Norwegian Data Protection Authority.

<http://www.datatilsynet.no/English/Regulations/Personal-Data-Act-/> last accessed 1.02.2016.

181 Implements Article 12 (a) third indent of the DPD.

182 Another difference is that section 25 is expressed as a right to demand the automated decisions being reviewed by a person, as explained in subsection 2.2. 
interpreted differently than in the underlying EEA law, and they must, therefore, be understood to be in conformity with Article $15(1)$ as it was interpreted in chapter $2 .^{183}$

As in Article 15(2), section 25(2) provides two exceptions to the right of demanding human involvement, namely authorization under a statute and if the data subject has agreed to an automated decision through a contract. ${ }^{184}$ The Norwegian lawmakers made three changes to the contractual exception. Firstly, they made the alternative condition of safeguards obligatory and removed the alternative condition of satisfaction. ${ }^{185}$ Secondly, they removed the possibility to exempt automated decisions when entering into a contract. And lastly, the lawmakers omitted the condition that the data subject must have been the party that requested the contract.

The second main question of this thesis consists of two assessments, firstly whether the Directive requires a complete or minimum harmonization of Article 15, and secondly what consequences this requirement has for the interpretation of section 25 of the Norwegian Act.

The reason for raising the question of harmonization is because section 25 , taken solely on its wording, apparently offers a higher level of protection than Article 15. The wording of the section still has to be weighed against other traditional sources of law, such as the preparatory works, to see whether it can be interpreted in conformity with the Article 15. But, the framing of this interpretation depends on the answer to the first assessment of harmonization.

Norway takes a dualistic approach to the relationship between its national law and international law. ${ }^{186}$ This means that Article 15, and the interpretations outlined in chapter 2 and 3 of the thesis, does not have direct application in Norway as the Directive must be transposed into national law. However, Norwegian case law applies a principle of harmonious interpretation, which presumes that the national legislation corresponds with Norway's international commitments. $^{187}$

183 Subsection 2.5 and 2.6.

184 The first exception of authorization through a statute will not be assessed here, for the same reasons as in subsection 3.1 .

185 Subsection 3.3.1.

186 The legal basis for this view is section 26 of the Norwegian Constitution, which demands approval from the Norwegian Parliament if the State is to enter into an international treaty. This has also been confirmed in case law and described in legal literature. See Rt-2000-1811 and Boe (2010) p. 110 and Arnesen (2015) pp. 18-19.

187 E.g. Rt-2000-1811 p. 1831 and Rt-2004-122 p. 31. In EU law this principle has also been called loyal interpretation or consistent interpretation. See further Prechal (2005) pp. 180-184. 
Therefore, the first question that needs to be answered is what the DPD requires in terms of implementation in the national legal system. More specifically, this question relates to whether the Directive demands complete harmonization across the EU/EEA, or if just requires minimum harmonization.

If the DPD requires full harmonization, then the principle of harmonization will guide the interpretation. If the answer to the first question is minimum harmonization, the second question still has to examine whether Norwegian law should be interpreted in conformity with Article 15, but without pressure from the principle of harmonization. ${ }^{188}$

The level of protection required in the EU is usually the same in the EFTA countries, ${ }^{189}$ according to Article 1 of the EEA agreement which states that the aim of the agreement is to promote "respect of the same rules, with a view to creating a homogenous European Economic Area." 190

First, I examine the question of harmonization (5.2), secondly the relationship between Article 15(1) and section 25 (subsection 5.3), and thirdly the relationship between Article 15(2) and section 25 (subsection 5.4). The questions are examined in this order as a pure interpretation of Norwegian sources of law does not take into account the underlying commitments in the EEA-agreement. ${ }^{191}$

\subsection{Complete or minimum harmonization?}

It is the Directive itself that determines whether it seeks complete harmonization between the Member States. ${ }^{192}$ The choice of form and method for implementing a Directive is generally left to the Member States discretion. ${ }^{193}$

188 A third question could be imagined, namely if Article 15 has direct effect. Then it would not require national implementation, such as in C-469/10 ASNEF. However, direct effect does not apply horizontally (between two private parties) which this thesis is limited to. See C-152/84 (Marshall). In addition direct effect does not bind Norway through the EEA agreement, e.g. Rt-2000-1811 and Fredriksen (2012) p. 280.

189 According to Kvam (2014a), it is uncontroversial to claim that the EEA-relevant legislation must conform to EU-law.

190 See also Article 3 of the agreement and section 4 of the Norwegian EEA Act which binds Norway to this principle of harmonization. In other words, if the EU law demands the full harmonization of Article 15, the same will apply for the other EFTA countries (except Switzerland).

191 Arnesen (2015) pp. 71-74 asserts that one should first interpret the international commitments, and secondly the interpretation of the Norwegian legislation. This has been criticized by Boe (2012) pp. 391-392. However, the main criticism by Boe is that Arnesen expresses this as a general rule, while he also points out that it has merits in specific cases.

192 Prechal (2005) p. 73.

193 Article 288(3) TFEU and Article 7(b) EAA agreement. 
The Directive has by some jurists been said to both provide provisions of maximum and minimum harmonization. ${ }^{194}$ However, this is not a satisfactory answer, as it does not provide a presumptive starting point for whether a provision seeks maximum harmonization in the situations where provisions do not regulate the question itself (such as Article 15).

The CJEU has made it clear that the Directive in general calls for a complete harmonization $^{195}$, based on Article 1 and recital 8 and 10 to the preamble. In C-473/12 (IPI) the Court stated:

31) It should be noted that the Court has previously held that Directive $95 / 46$ amounts to harmonisation which is generally complete (see Case C-101/01 Lindqvist [2003] ECR I-12971, paragraphs 95 and 96, and Huber, paragraphs 50 and 51). However, the Court has also found that the provisions of Directive 95/46 are necessarily relatively general given that it has to be applied to a large number of very different situations, and that the Directive includes rules with a degree of flexibility and, in many instances, leaves to the Member States the task of deciding the details or choosing between options (Lindqvist, paragraph 83).

Thus, the starting point is complete harmonization as long as the Directive itself does not provide exceptions or options. ${ }^{196}$ As I see it, the CJEU has summarized the possibility of derogation through three exceptions, namely when "rules include a degree of flexibility"197, when a provision allows the Member State "a margin of maneuver"198, or when the Member State has extended the scope of the national legislation to "areas not included within"199 the Directive.

It can be argued that Article 15 has an ambiguous wording, but not in a way that gives it flexibility as to which conditions must be implemented. The provision states that the Member States "shall grant" a right and "shall provide" exceptions. In comparison Article 10 of the

194 See for example Blume (2003) p. 25 and Schartum (2011) pp. 88-89. Several Norwegian sources of law indicate that Norway in general is afforded the possibility of providing a higher level of protection than the Directive offers (minimum harmonization), such as NOU 2009:1 subsection 6.2.4.2, the Data Protection Tribunal in PVN-2014-1 (point 6). This view has been challenged by Kvam (2014b) pp. 57-63.

195 The question has been raised in the following cases: Rechnungshof v. Österreichischer Rundfunk (C465/00), Lindqvist (C-101/01), Huber (C-524/06), ASNEF (C-468/10) and IPI (C-473/12).

196 Also argued by Heil (2006) pp. 14-15.

197 C-473/12 IPI (recital 32).

198 C-101/01 Lindqvist (recital 97) and recital 9 to the preamble.

199 Ibid (98). 
DPD uses the wording "at least" when describing what information the data subject shall be given.

In addition, no provision gives the Member States a margin of maneuver when it comes to Article 15. Article 5 of the DPD says that a member state may determine "more precisely the conditions under which the processing of personal data is lawful." However, Article 5 is not applicable in this instance, as it understood to only give the Member States the discretion for a "mere clarification" of the provisions. ${ }^{200}$

Nor is the third exception constructed by the CJEU applicable to the changes made by the Norwegian lawmakers. "Areas not included" by the Directive should be understood as the competence to expand the provisions to other legal fields, such as public security, defense and state security, which are not within the scope of the DPD, according to Article 3 (2).

As mentioned in relation to C-473/12 (IPI), the reasoning of the Court builds on Article 1(2) and the preamble recital 8 and 10 that states the Member States shall not restrict the free flow of personal data. Therefore, one could argue that the rulings of the CJEU should not be applied to Article 15, as the provision does not regulate the lawfulness of processing and thus not the flow of personal data directly. The purpose of Article 15 is to grant individuals a right not to be subject to automated decisions and does not concern itself with the legality of the processing.

However, the omission of the profiling condition will, in theory, put more obligations on private companies in Norway than in the other contracting parties to the EEA-agreement. The exercise of the right to demand human involvement, as seen in subsection 2.3, might indirectly influence how the decision maker processes the data which leads to the decision. This might de facto restrict the free flow of data between the contracting parties.

Thus, the conclusion to question one is that Article 15 demand complete transposition into the Member States legal orders.

\subsection{Harmonization between Article 15(1) and section 25}

The profiling condition stipulates that the automated decision has to be based on an automated process with the intention to evaluate certain personal aspects relating to the data subject. If the Norwegian Act is to be read straightforwardly, it means that section 25 encompasses all

200 C-468/10 ASNEF (34 and 35). 
automated decisions, without regard to what data the decision was based on. ${ }^{201}$ This means, for example, that a data subject could have the right to demand human involvement when an ATM machine refuses to give a person cash withdrawal, or other banal automation. ${ }^{202}$

Turning to the second question, the starting point is clear; section 25 does not contain the profiling condition. Thus, the Norwegian implementation of Article 15 is, in principle, in conflict with the requirement under the EEA agreement. ${ }^{203}$ The following assessment is whether section 25 can be read as containing the profiling condition, which consequentially limits the scope of the provision.

The principle of harmonious interpretation is of relevance in this examination, and this method was explored by the Norwegian Supreme Court in Finanger I. ${ }^{204}$ The Court held that the interpretation of Norwegian law still relies on the acknowledged methods of interpretation, but EEA conformity constitutes an important source of law in the analysis. ${ }^{205}$ If the Norwegian legislators deliberately omitted the condition for the purpose of widening the scope of the provision, then the Norwegian Courts will not have the liberty to interpret the condition into section $25{ }^{206}$ Thus, a harmonious interpretation is possible if the omission was unintentional.

The transposition of Article 15 into the Personal Data Act was reviewed in three instances, first by the Committee of 1997 in charge of revising the Personal Data Register $\mathrm{Act}^{207}$, secondly the Ministry of Justice ${ }^{208}$ and lastly by the Standing Committee on Justice in the Norwegian Parliament. ${ }^{209}$ The preparatory works were written before the formal inclusion of the Directive in the EEA agreement, but all the instances took into account the Directive as it was of EEA-relevance and was assumed to be adopted by the EEA council. ${ }^{210}$

\footnotetext{
201 It seems that, as a consequence of splitting up Article 15 into the three sections, the profiling condition only appears in section 21 . This section gives the data controller the duty to notify the data subject when applying profiling techniques. It seems strange that the profiling condition from Article 15 appears in this section, as the obligation it gives is not part of the DPD. The GDPR has a new provision that is reminiscent of section 21, namely Article 13(2) (f).

202 The Commission did not intend for these automated decision to be encompassed by the Article. See COM 422 (1992) p. 26.

203 The Norwegian EEA Act section 2 does not regulate the question of conflict, as it presupposes a Norwegian implementation. See Rt-2000-1811 (p. 1827).

204 Rt-2000-1811.

205 Ibid p. 1832.

206 Ibid.

207 NOU 1997:19. In Norwegian: Personregisterlovutvalget.

208 Ot.prp.nr.92 (1998-1999).

209 Innst.O.nr.51 (1999-2000).

210 NOU 1997:19 p. 70 and Ot.prp.nr 98(1998-1999) p. 16.
} 
The Committee of 1997 proposal for section 25 included the profiling condition (my translation):

The person a decision is directed towards or whom the decision otherwise directly concerns, may demand that the personal data must be processed manually if the decision

1) Is a decision as defined in $\S 2$ paragraph 9 or otherwise has significant effect on the person, and

2) Is based solely on automated processing, and

3) Characterizes personal abilities.

It is clear that it was not the Committee's intention to make the section applicable to other automated decisions not based on profiling. However, the Ministry of Justice changed the wording of the provision from "characterizes personal abilities" to only stating that the automated process had to be of "personal data." At the same time, the Ministry stated that (my translation):

The provision follows up the Committee's proposal for $\S 27$, which implements Article $15 \mathrm{nr} 1$ of the Directive. The Ministry has given the provision a slightly different design, but its substance corresponds to a large degree with the Committee's proposal. ${ }^{211}$

The omission of the condition was not mentioned by the Standing Committee on Justice. They did not make any amendments and only reiterated the views of the first Committee and the Ministry, as they assumed that section 25 corresponded to the Directive, despite the changes to the formulation of the conditions. ${ }^{212}$

In conclusion, the preparatory works of section 25 do not completely clarify whether the change from "characterizing personal abilities" to "personal data" was intentional or not. However, both the statement that section 25 is meant to implement Article 15 of the DPD and that the final design was not intended to change its substance suggests that the profiling condition was not willfully omitted.

In Finanger I the Supreme Court ruled that there was an apparent conflict between the Norwegian provision and the underlying EEA law, and the Court found that they could not interpret the provision in such a way to make it comply with the Directives. ${ }^{213}$ Part of the reason was that the principle of harmonious interpretation does not carry the same weight in disputes

\footnotetext{
211 Ot.prp.nr 98 (1998-1999) p. 124.

212 Justiskomiteeen (2000) point 5.4.

213 Rt-2000-1881 (p. 1830 and 1832).
} 
between private parties (horizontal application). The Court also stated that it is not up to the judiciary to surmise what the other state branches of power would have done had they been aware of inconsistent implementations. ${ }^{214}$

However, even though the question in point has some similarities to Finanger I, there are dissimilarities between them. The first difference is that in Finanger I the Supreme Court would have had to interpret the text of the Act as non-existent, in order to completely harmonize the Norwegian provision with EEA law. The question for the Court was whether a provision that reduced the damages a person could claim should be interpreted restrictively, as it was not in compliance with EEA law. ${ }^{215}$

The question put forward here is whether a condition should be read 'into' the provision. It can be argued that this method of interpretation interferes less with the responsibilities of other state branches of power, as legal text is not actually omitted from the legislation.

A second difference is that the ramification of the harmonious interpretation in Finanger I would have been more severe than in the harmonization of section 25. Had the Court come to a different result, Finanger I would have burdened one of the parties financially, ${ }^{216}$ and it would have made compliance with Norwegian law harder, which can be said to contradict a principle of predictability.

In my opinion, it ought to be a deciding factor that adding the profiling condition to section 25 does not burden any private party financially. In contrast, this will ease the obligations some private companies might have if the profiling condition is to be omitted. It can also be argued that Norwegian citizens will not suffer any significant loss to their privacy in having the profiling condition read into section 25 . Thus, the conclusion is that section 25 must be read as containing the profiling condition.

\subsection{Harmonization between Article 15(2) and section 25}

As mentioned in the introduction, the Norwegian lawmakers made three changes to the exception. By changes, I refer to modification in the legal text alone. The first difference is that only automated decisions in the performance of a contract are legal, and not when entering into a contract. Secondly, the lawmakers omitted the condition that the data subject must have been the one to request the contract.

\footnotetext{
214 Rt-2000-1881 (p. 1833).

215 Section 7(3) b Automobile Liability Act (as of 01.01.2001) and Directives 72/166/EEC, 85/5/EEC and 90/232/EEC.

216 Rt-2000-1811 (p. 1833). The insurance company complied with the written legislation and not EEA law.
} 
The last change is that the decision maker does not have the possibility to exempt the automated decision through satisfying the contractual request made by the data subject (see subsection 3.3.1). Instead, the other alternative condition of safeguards has been made obligatory (see subsection 3.4). I will deal with the differences in this order.

In principle, the wording of the contractual exception is clear; it is only the performance of a contract which is exempted. However, as argued in the previous subsection, compliance with the Directive is a strong argument for harmonizing Article 15 (2) and the contractual exceptions given in section 25. The Committee of 1997 included "entering into" a contract as an exception. This was later removed by the Ministry of Justice in the final text. But, the Ministry nevertheless stated that (my translation):

With regard to the exception for decisions that relates to the entering into or performance of a contract, it is important to highlight that there is a requirement of implementing suitable measures to safeguard the person's legitimate interests. ${ }^{217}$

The Standing Committee on Justice also referred to the contractual exception as either taking place when entering into or in the performance of a contract. ${ }^{218}$ It seems that all the instances intended to include an exception for when the data subject enters into a contract with the decision maker. Thus, the conclusion is that the condition should be read into section 25(2).

Similarly, the requirement that the data subject has to be the party requesting the contract, was also mentioned by the Committee of $1997 .{ }^{219}$ Yet, the Committee did not include the condition in their proposal. The reason for this is not specified, which indicates that it was not willfully omitted. As opposed to the other changes made by the Norwegian lawmakers, the removal of this requirement, in theory, lowers the level of protection for the individual. Thus, there is a greater reason for harmonizing section 25 with Article 15(1) here. Subsequently, the conclusion is that the data subject must have been the party requesting the contract under section 25(2).

The third and final difference between section 25 and Article 15(2) is the removal of the alternative condition of "satisfaction". The consequence of this is that the other alternative condition of safeguards has been made obligatory for the contractual exception. It is difficult to tell whether this change actually increases the level of protection for the data subject.

\footnotetext{
217 Ot.prp.nr 98 (1998-1999) p. 47.

218 Innst.O.nr.51 (1999-2000) point 5.4

219 NOU 1997:19 p. 69.
} 
However, the fact is that the Norwegian lawmakers restricted the possibilities of derogation. In the preparatory works, on the other hand, the condition of satisfaction is mentioned in several places:

"If the automated decision involve that the data subject is not made an offer to enter a contract, the right to demand re-examination will apply."220

The reason why the Committee of 1997 did not include the condition of satisfaction might be that they looked at the approval of a contractual request precisely as a safeguard. This is a possible interpretation of section 25(2), even without an explicit foothold in the preparatory works. The argument of harmonizing Norwegian law with the Directive is alone a strong enough argument for this understanding of "safeguard" in section 25(2). In other words, the conclusion is that if the decision maker has satisfied a contractual request made by the data subject they cannot be required to implement safeguards beyond the contract itself.

In summary, the answer to the second main question is that section 25 must be interpreted in complete harmonization with Article 15. Thus, section 25 will presumably have the same scope as Article 15, and the Norwegian implementation is in compliance with the Directive.

220 Ot.prp. nr 98 (1998-1999) p. 124. See also p. 47 and NOU:1997:19 p. 70. 


\section{$6 \quad$ Article 22 of the GDPR}

\subsection{Introduction}

Article 15 of the DPD is continued under the General Data Protection Regulation in Article 22. At the outset, the wording of Article 22 can seem quite similar to that of Article 15 with just a few changes. A closer look at the provision, however, will prove that some substantive changes cause an expansion of the provisions scope, especially in regard to the derogations in paragraph 2. This chapter will examine the third main questions under the thesis, namely if Article 22 provides a higher level of protection than Article 15 of the DPD.

The Commission first proposed the GDPR in 2012, and it was a topic for negotiations until it was resolved in a trialogue between the Commission, the Parliament, and the Council in midDecember of 2015. The continuation of Article 15 as Article $22^{221}$ was amongst the topics of the trialogue, and the text that came out of the negotiations is not identical to any of the previously proposed provisions.

The trialogue raises some methodology problems because the actors' statements are not publicly available. ${ }^{222}$ As a result, it is difficult to find the legislative reasons for the final text, besides the wording itself. There are, however, several texts from the EU Institutions and other stakeholders leading up to the trialogue, which can be of assistance in the examination of the new provision.

Article 22 is systematized the same as that of Article 15. The first paragraph gives the data subject the right not be subject to automated decisions, and paragraphs 2 and 3 deals with the exceptions to that right. The last paragraph introduces a prohibition of automated decisions based on special categories of data, ${ }^{223}$ which is new in regard to Article 15 . Article 22 reads as follows:

221 It was proposed as Article 20 in COM/2012/11 Final. (Since all the preparatory works had not been officially released as of the writing of this thesis, the references I use is linked to the appropriate document in the bibliography. See footnote 270.)

222 The trialogue is an informal process of negotiations between the Commission, Parliament and Council. It is believed to be more effective than the more formal procedures of lawmaking under the treaties of the European Union. It has on the other hand been described as a policymaking in "black box", because there is not much transparency in the process. See Borońska-Hryniewiecka (2015) p. 5.

223 Article 9, on special categories of personal data, continues Article 8 from the DPD. 
Article 22 Automated individual decision-making, including profiling

1. The data subject shall have the right not to be subject to a decision based solely on automated processing, including profiling, which produces legal effects concerning him or her or similarly significantly affects him or her.

2. Paragraph 1 shall not apply if the decision: (a) is necessary for entering into, or performance of, a contract between the data subject and a data controller; (b) is authorised by Union or Member State law to which the controller is subject and which also lays down suitable measures to safeguard the data subject's rights and freedoms and legitimate interests; or (c) is based on the data subject's explicit consent.

3. In the cases referred to in points (a) and (c) of paragraph 2, the data controller shall implement suitable measures to safeguard the data subject's rights and freedoms and legitimate interests, at least the right to obtain human intervention on the part of the controller, to express his or her point of view and to contest the decision.

4. Decisions referred to in paragraph 2 shall not be based on special categories of personal data referred to in Article 9(1), unless point (a) or (g) of Article 9(2) apply and suitable measures to safeguard the data subject's rights and freedoms and legitimate interests are in place.

One of the changes that may be significant is the addition of an explicit profiling definition. Hence, it is important to examine whether this changes the scope of the provision. The derogations of the provision are considerably tighter compared with the DPD, even though there is a new exception for consent. ${ }^{224}$ This has to do with an increase in mandatory safeguards, requirements of proportionality, and a right of human intervention. ${ }^{225}$

Subsection 6.2 deals with the rationale of Article 22, and the main topic is whether it has changed. Then follows an examination of the new structure of Article 22, an analysis of the new profiling definition, and lastly whether the right given in the first paragraph should be understood as a prohibition or a right (6.3). Next, I will address the new exceptions, namely the contract with the data subject (6.4) and explicit consent (6.5). The regulation of sensitive

\footnotetext{
224 Article 22(2) c. As in the examination of Article 15(2) in chapter 3, this chapter does not examine the exception concerning member state law in Article 22(2) b. The GDPR has not entered into force yet, and there are presumably no such exceptions in national law or union law yet.

225 Article 22(3)
} 
data appears in subsection (6.6). Lastly, I will examine the practicality of the provision, with examples from online scoring techniques, weblining, and OBA (6.7).

\subsection{The rationale behind Article 22}

The purpose of Article 15 of the 1995 Directive was to combat both important automated decisions and profiling. Human presence in machine operations is not something that necessarily makes the decision more accurate or correct, but it is necessary in important decision making so that individuals are not judged by a computer alone. As long as we interpret Article 22 as just a continuation of Article 15, there is no reason to say that the rationale is different. But, as the following subsection shows, there were many proposed changes to the provision and a struggle among various actors on how to regulate both automated decision making and profiling. ${ }^{26}$ There were approximately 3,100 proposed amendments to the entire GDPR in the European Parliament. ${ }^{227}$

The final wording of Article 22 is not exactly similar to any of the proposals from the Commission, Parliament, or the Council. It is, however, closest to the Council's amendment. ${ }^{228}$ Both the Commission and the Council agreed that the provision needed to target both automated decisions and profiling. Parliament went the furthest, as they wanted to give individuals a right to object to all profiling and not just the decisions that might arise from profiling. ${ }^{229}$ However, all the institutions agreed that some decisions based on profiling should be harder to carry out, namely the decisions based on sensitive data as regulated in Article 9 in the GDPR.

An immediately noticeable difference between the DPD and the GDPR is that the lawmakers focused more on profiling as a concept, a subject that legal literature has addressed in a more detailed manner since the adoption of the DPD. For instance, the title of the provision was has changed from Automated individual decisions to Automated individual decisions, including profiling. This can also be seen by the introduction of "profiling" in the legal text, instead of the long and strenuous term "automated processing of data intended to evaluate certain personal aspects relating to him."

Different actors in the industry also stressed the positive sides of profiling in the lawmaking process. Two committees in the European Parliament, namely the Internal Market and Consumer Protection (IMCO) and the Committee on Industry, Research and Energy (ITRE), were more friendly minded to this technology than the Albrecht report from the Committee on Civ-

\footnotetext{
226 An extensive summary is offered by Vermeulen (2013)

227 Calculated by LobbyPlag (2013) < http://www.europe-v-facebook.org/LP_en.pdf > last visited 16.05.2016

228 Doc. 15395/14

229 2012/0011(COD) Article 20(1)
} 
il Liberties, Justice and Home Affairs. ${ }^{230}$ The Albrecht report wanted a broader Article 22 and more limitations for profiling, which included prohibition in more circumstances than the current version. IMCO and ITRE were skeptical to some of these amendments, and ITRE proposed exceptions to Article 22(1) in the areas of advertising, market research, and tailored media while stating that:

"[t]he original wording of Article 20 could lead to companies having to obtain consent for any form of processing personal data. In order, however, not to destroy the business models of countless small and medium-sized European companies in particular, and thus give priority to large US firms, certain forms of data processing should be allowed with due respect to the protection of personal data."231

Lastly, the protection of children has to be mentioned. ${ }^{232}$ The preamble states that children should, in particular, be protected against "creating personality or user profiles." 233 This will clearly have a consequence for the interpretation of what is significant decisions for children.

In conclusion, based on the language of Article 22 we can see the Article as a direct continuation of Article 15 of the DPD, but the rationale behind the provision has somewhat changed, as there is more emphasis on combating profiling than was the case under Article 15.

\subsection{The structure of Article 22(1)}

\subsubsection{Change of condition 1? Profiling as a basis for decision-making}

This subsection examines the substantive changes to the first paragraph of Article 22. The right still consists of three conditions. Two of these conditions are exactly the same as in the DPD - that an automated decision must be based solely on automation, which either has legal or significant consequences. ${ }^{234}$

The third condition is different: the basis for the decision must have been an "automated processing, including profiling." Under Article 15 this was instead "automated processing of data intended to evaluate certain personal aspects" relating to the data subject. The new design of the profiling criterion might raise some issues as to the structure of the provision.

\footnotetext{
230 Amendments 181 to196 by Albrecth (2013)

231 Vermeulen (2013) p. 24.

232 SEC(2012) 72 p. 60.

233 Recital 38.

234 The similar conditions are covered in chapter 2.
} 
The question is if the addition of "including profiling" means that profiling as a concept deserves treatment separate from automated decisions, or if it means that profiling is an example of an automated process. In other words, does the wording of "including" refer to the condition of decision, or does it refer to the condition of automated processing?

Thus, the structure of Article 22 can be interpreted in two ways, as shown in the figures below:

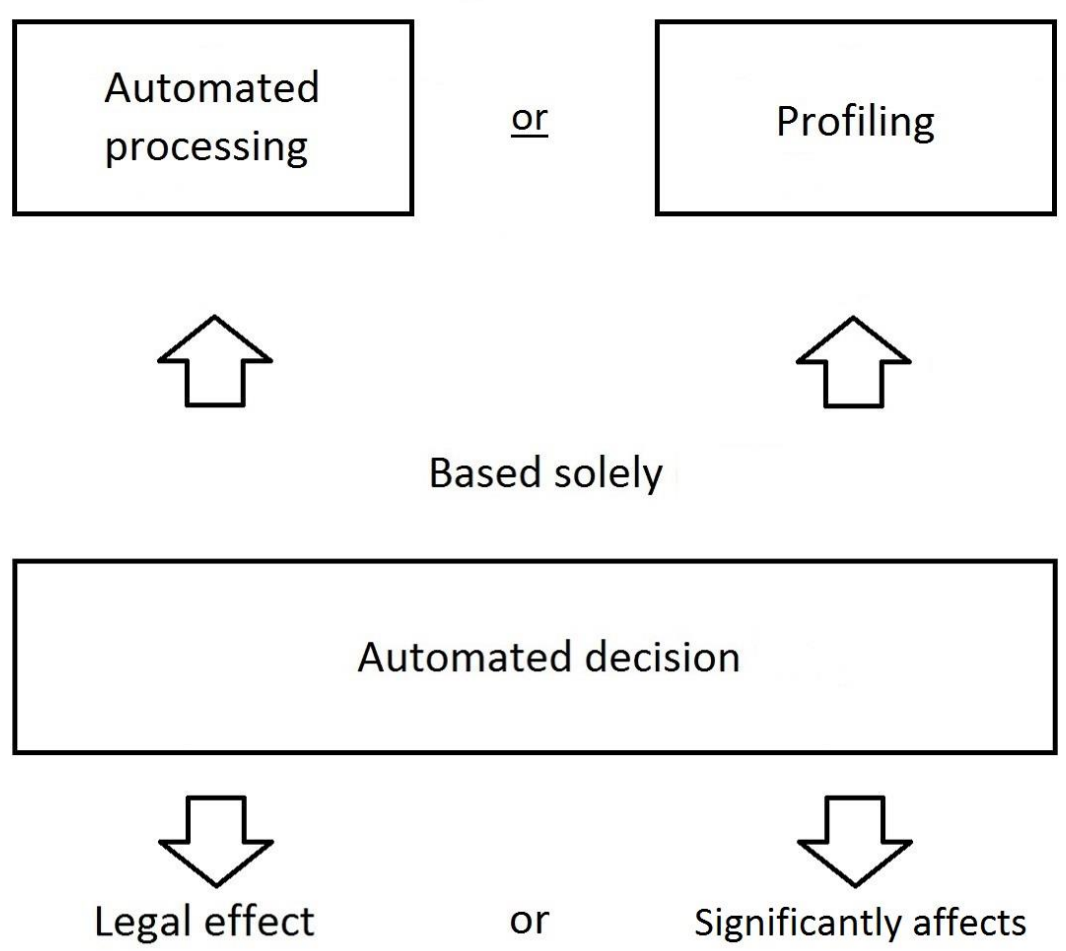

Figure 2

In this figure, "including profiling" is a type of automated processing and therefore an alternative basis for automated decisions that falls within the scope of the Article. 


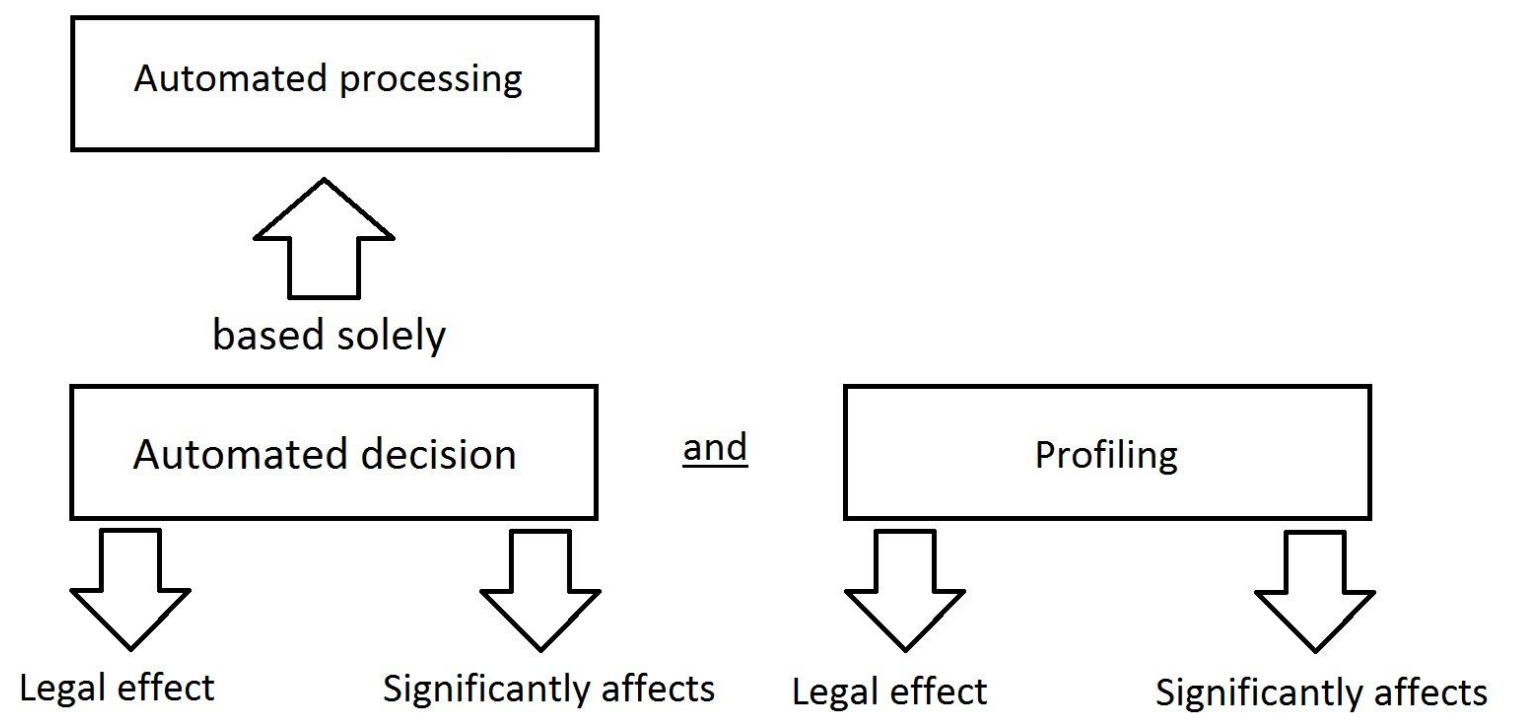

Figure 3

Figure number 3 interprets "including" as referring to automated decisions and thus a separate concept that the provision encompasses. The consequence of this understanding is that the profiling activity does not need to lead to a decision for the data subject to have a right not to be subject to it.

The wording of "including profiling" raises two problems. The first is that both figures leave unanswered the question of what "automated processing" is if it is not profiling. The second problem, relating to figure 3 , is whether the provision encompasses profiling as an individual concept.

To start off with the first problem, the wording of "automated processing" indicates that it may form a basis for an automated decision. ${ }^{235}$ Even though the Article does not explicitly mention that the automated processing must be personal of personal, this follows from the scope of the GDPR. ${ }^{236}$

235 Processing is similarly defined in Article 4(2) as in Article 2(b) DPD.

236 Article 2(1) GDPR. 
However, if the condition of automated processing is to have an autonomous purpose, it cannot be such a processing that would constitute profiling. A use of Article 22 without the decision being based on a profile would make Article 22 broader in scope than Article 15 of the DPD. Virtually all automated decisions targeting a person would fall within this rule, as for instance, the refusal of taking out cash from an ATM machine.

Article 15 of the DPD dealt with this problem by saying that the automated processing had to have the intention of evaluating the person, meaning that the decision had to be based on a profile of the individual. This structure combined the condition of an automated process with the idea of profiling, while Article 22's wording separates these two ideas with the term "including."

The other language versions to the GDPR also contains the unfortunate wording of "including profiling". Neither does the preamble explain why the text of "including profiling" was added. ${ }^{237}$ As examined in the previous subsection, the preparatory works of the GDPR focus mainly on the harms of profiling, not all automated decisions targeting a human being. Thus, the rationale behind the rule does not support the use of the condition "automated processing" without including profiling in the application of the provision.

Therefore, it can be concluded that automated processing should be read as processes that involve profiling. This is, however, an unnecessary exercise, as Article 4(4) defines profiling as a type of automated processing. In conclusion, the condition of "automated processing" either broadens the scope of the provision too much, which goes against the rationale behind the Article, and should therefore be omitted from its reading, or it is superfluous and could likewise be excluded.

The second problem is whether profiling as an automated process falls within the scope of the provision without it leading to a decision (see figure 3 ). The second problem is less significant than the first, as most profiling activities in practical terms must result in decision for the data subject to be aware of its existence. The interpretation will, on the other hand, have significance for when the data processor duty to give notice of profiling takes places, under Article 13(2) f. Is it first when a decision has been made, or when the profiling occurs?

Taking into account the new title of the paragraph, which is Automated individual decisions, including profiling, one could argue that the provision includes both profiling and automated

237 See especially recital 71. 
decisions as two separate concepts. Again, it is the addition of the word "including" that makes the scope of Article 22 ambiguous.

The decisive element in this interpretation is nevertheless the fact that the previous interpretation of automated processing proved the necessity of omitting it from the reading of the provision. The effect is that the interpretation shown in figure 3 would not make the Article operable, in which case the only possible understanding of the Article is the one figure 2 shows. Nothing in the preamble, preparatory works or in the rationale behind Article 22 supports another conclusion. As seen in the previous subsection, a proposal for regulating profiling individually without the necessity of an automated decision was expressly abandoned in favor of an approach that was more in line with Article 15 of the DPD. ${ }^{238}$

One could imagine a third figure in which profiling as an individual concept, and an automated decision based on profiling was part of the same provision. However, this is an odd understanding of the provision. The condition of decision would be impractical, as it is easier to just prove that profiling itself has taken place. This is also the solution that fits the least with the wording of the Article. Article 22 suffers from the fact that the text itself was poorly formulated with the ambiguous wording of "including profiling."

Nevertheless, considering both the rationale behind the Article, the preamble, and the preparatory works, the conclusion must be that automated decisions based on profiling is the right interpretation of the provision (figure 2), but "automated processing" must be omitted from its application.

\subsubsection{Profiling as a legal concept}

The GDPR defines profiling explicitly. The reason for including this definition in the GPDR was to avoid uncertainty as to what constitutes profiling, as the different Member States could apply their national legislation differently. ${ }^{239}$ Article 4(4) reads as follows:

'profiling' means any form of automated processing of personal data consisting of using those data to evaluate certain personal aspects relating to a natural person, in particular to analyse or predict aspects concerning that natural person's performance at work, eco-

\footnotetext{
238 It can also be argued that profiling as a process is regulated by Article 21(1) and (2), where the data subject has the right to object to such processing based on his "particular situation". The same reasons given in subsection 1.5, as for the differences between Article 14 and 15 in the DPD, still applies to the relation between Article 21 and 22 in the GDPR.

239 SEC(2012) 73 p. 24 and Vermeulen (2013) p. 5.
} 
nomic situation, health, personal preferences, interests, reliability, behaviour, location or movements $[\ldots]$

The new definition of profiling consists of two elements. First, it requires that there be an $a u$ tomated process of personal data. As covered in the previously in the thesis ${ }^{240}$, regarding Article 15 , virtually all handling of personal data by mechanical means constitutes automated processing. And secondly, the use of the personal data must be to evaluate certain personal aspects relating to a natural person.

A difference to the DPD is that the new definition has more examples of what constitutes profiling. It is not limited to performance at work, creditworthiness, reliability, and conduct, but also health, personal preferences, interests, reliability, behavior, location, or movements. This expansion of examples is in line with the focus on profiling in the preparatory works.

Another difference to the DPD is that the definition of profiling does not include the criterion of "intention". ${ }^{241}$ This means that problems Savin laid out, such as where profiling is an ancillary effect ${ }^{242}$, is avoided and falls within the scope of the provision. However, it also excludes the situations in where the decisions maker has attempted to profile the data subject from the scope of Article 22. Still, it can be argued that such attempts fall within the definition, as Article 4(4) does not require any correctness of the profiling.

A third difference to how profiling was understood in Article 15, is that the definition does not contain the terms "personality." Neither does any of the other language versions include this word. Instead, they contain variations of the term "personal aspects". This is, however, of little significance as what constitutes profiling has been greater elaborated in the GDPR, and it is reminiscent of the assessment as laid out in subsection 2.4.2. Article 4(4) mentions for instance processing that analyzes or predicts the behavior of a person. The line drawn between what is processing of "straightforward factual data" and processing activities that are more "subjective" will presumably be sustained. ${ }^{243}$

Vermeulen believes that the reference to a "natural person", and not a data subject in Article 4(4), means that profiling not based on personal data also falls within the scope of Article

\footnotetext{
240 Subsection 2.4 .

241 See subsection 2.4.2.

242 Savin (2014) p. 4.

243 Korff (2005) p. 49.
} 
22. ${ }^{244}$ The Council proposed changing this wording. Nonetheless, in the final draft, the actors agreed to a definition of profiling that references personal data.

In conclusion, it can be observed that the GDPR is different from the DPD in the fact that profiling appears as a legal term with a precise definition. But the material content of what constitutes profiling is not different.

\subsubsection{Article 22 - right or a prohibition?}

The right under Article 15 of the DPD was understood as a right of human involvement, without it having significance if the Member States implemented it as a right the data subject needed to exercise or in fact as a prohibition (subsection 2.2). The wording is ambiguous; the data subject shall have the "right not to be subject." This ambiguity suited the DPD well, as the Directive gave the Member States some margin of appreciation in the implementation. ${ }^{245}$ The GDPR is, on the other hand, a Regulation. Thus, Member States is required to incorporate the Articles word for word. ${ }^{246}$ As a result, it is necessary to clarify this question here.

It is clear that the Article 22 gives the decision maker a possible obligation of not subjecting the data subject to automated decisions, and the data subject a corresponding right, without regard to how one interprets the provision. The question, however, is whether the right needs to be exercised or not.

There are several rights in the Regulation that apparently requires the data subject to exercise them, such as the right to object to the processing of personal data (Article 21), the right of erasure (Article 17), and right of rectification (Article 16). The problem with Article 22 is that the data subject does not have the right to something but the right not to be subject to a decision. This distinction suggests that the lawmakers meant to make Article 22 a prohibition and not a right the data subject has to use.

Compared with how the lawmakers have formulated prohibitions in data protection law, Article 22 can appear to be a right. Paragraph 4 of the provision says that automated decisions "shall not" be based on special categories of data. One could argue that the lawmakers presumptively would have formulated paragraph one more like paragraph 4 if the right was not to be exercised by the data subject. Also, the corresponding provision on automated decisions in

244 Vermeulen (2013) p. 8.

245 E.g. France and Germany transposed it as a prohibition, and UK and Norway as a right the data subject needed to exercise.

246 Craig (2011) p. 105. For the Member States Regulations will also have direct effect even though it is not transposed into national law, according to Article 288 of the TFEU. 
the Data Protection Directive for the Police and Justice Sector, which lawmakers negotiated at the same time as the GDPR, reads as follows:

Member States shall provide for a decision based solely on automated processing, including profiling, which produces an adverse legal effect concerning the data subject or significantly affects him or her, to be prohibited unless authorised by Union or Member State law $[\ldots]^{247}$

Overall, the interpretation of the text seems uncertain. However, considering that Article 22(3) has included the safeguard of human involvement, as an exception, it would not make sense to understand Article 22(1) as giving the same right. Thus, the right provided by Article 22(1) does not have to be exercised; it is in other words a prohibition, which creates an obligation to which the decision maker has to comply. This is without regard to whether the data subject has invoked it or not.

\subsection{Article 22(2) (a) and (3) - the contractual exception \\ 6.4.1 Condition 1: entering into or performance of a contract}

The contractual derogation is carried forward in the GDPR, but with changes to it that make it a more limited exception. The condition of suitable measures to safeguard the interests of the data subject, which was an alternative under Article 15 of the DPD, is now a mandatory condition that always has to be fulfilled for the contractual exception and the exception for the data subject's consent. I assess the contract exception first and then the condition of suitable measures (6.4.2):

2. Paragraph 1 shall not apply if the decision: (a) is necessary for entering into, or performance of, a contract between the data subject and a data controller; (b) is authorised by Union or Member State law to which the controller is subject and which also lays down suitable measures to safeguard the data subject's rights and freedoms and legitimate interests; or (c) is based on the data subject's explicit consent.

3. In the cases referred to in points (a) and (c) of paragraph 2, the data controller shall implement suitable measures to safeguard the data subject's rights and freedoms and legitimate interests, at least the right to obtain human intervention on the part of the controller, to express his or her point of view and to contest the decision.

\footnotetext{
247 Article 11 EU 2016/680.
} 
The first apparent difference is that the lawmakers added the word necessary to the contractual exception. The wording indicates that the automated decision must have been required for the purpose of entering into or fulfilling the contract with the data subject. But what degree of necessity is required before a contract needs to incorporate automated decision making is left unanswered. Neither the preamble nor the preparatory works specify the meaning of this criterion.

The wording of necessary cannot be interpreted too strictly, as it is hard to think of an example where an automated decision had to happen without human involvement. The rationale behind this condition is presumably to make it more difficult for the data controller to escape Article 22 by merely pointing to a standardized contract with the data subject. But sometimes automated decision making is in the data subject's interests, such as a rapid approval for a payment deferral in an online shop. It is possible to argue that automated credit scoring is not necessary, as a person could do it, but it still makes it cheaper for the lender to consider making the loan.

Article 15(2) stated that the automated decision had to be made in the course of entering into a contract with the data subject. This was in subsection 3.2 understood as a requirement of a relation between the material content of the contract and the need for an automated decision. This is the same type of assessment the term "necessary" points at, but the level of protection should be higher under Article 22 as the lawmakers explicitly added it to the wording.

Thus, the criterion of necessity can be seen as an expression of the principle of proportionality. This principle has been increasingly used in EU data protection law, especially case law. ${ }^{248}$ Consequently, it can be argued that the "necessary" should be interpreted as a relative condition, and measured against the nature of the contract.

A question that is left unanswered is whether an automated decision becomes necessary if it is simply a part of the terms of the contract. It is possible to argue that it is necessary to perform the automated decision as this is part of the obligatory contractual terms. If this is the case, then it would not be difficult to escape this new condition by only making the data subject enter into a supplementary contract, before the automated decision takes place. However, this was presumably not the intention of the lawmakers. But the final demarcation of what is necessary is not possibly to draw based on the wording alone and should for that reason be left to the courts.

248 Bygrave (2014) pp. 147-148. See also recital 4 to the preamble. This principle is generally stated in the three assessments of suitability, necessity and non-excessiveness (proportionality strictu sensu). 
Lastly, the condition that the data subject must have been the one to request the contract is also removed from Article 22. This has arguably limited the protection under this exception, as now contracts that the data controller requests are applicable. Yet, the additional condition of suitable safeguards has been tightened, which as a whole gives the data subject a higher level of protection. This condition is assessed in the following.

\subsubsection{Condition 2: safeguards and the right of human intervention}

The wording of suitable measures, is almost the same as Article 15, which calls for a similar interpretation of Article 22. The condition is relative, meaning that the required safeguards have to be measured against the significance of the automated decision. However, the data subject, regardless of the importance of the decision, shall have the right to "express his or her point of view and to contest the decision." This means that the data controller has the obligation to facilitate the response and views of the data subject.

Furthermore, the level of protection under Article 22(3) is considerably higher since the provision now explicitly mentions that the data subject shall "at least" have the right to "obtain human intervention." This is arguably the most significant difference between Article 15 of the DPD and Article 22. The reason for this is that there will be little difference in the level of protection between the right offered in Article 22(1) and the exceptions.

The conclusion in subsection 2.2 was that no matter how the Member States implemented Article 15, either as a right to be exercised or as a prohibition, it would in fact work as a right to human involvement in automated decision making. The same line of reasoning applies to the right under Article 22 even though it works as a prohibition.

For that reason it seems odd that the data subject still retains the right of human involvement even though the he has entered into a contract with the decision maker or given his consent for the automated decision. One could argue that there is a difference between a prohibition and a right that needs to be exercised. However, if the decision maker at the same time has the obligation to facilitate the data subject's point of view, it would be reasonably practical to exercise the right.

An online bank might, for example, be required to prompt the data subject for his or her view in an online form and at the same time give him the possibility of requesting the human involvement of an employee of that bank. The wording "at least" does therefore not add up, as human re-examination must be the best safeguard the data subject can hope for. 
One may question whether the safeguard of human intervention should be read and applied according to its wording. Paragraph 4 of Article 22 will no longer have any independent effect if the data subject is to retain his right to human involvement. Paragraph 4 prohibits fully automated decisions based on special categories of data, and this prohibition would de facto be protected through paragraph three.

However, the Commission, Parliament, and the Council all at some point in the lawmaking process proposed human involvement as a safeguard. ${ }^{249}$ It does, therefore, seem quite certain that the lawmakers intended for this exception to be read according to its wording. And there are no other sources of law that contradict this interpretation beyond the de facto inconsistencies the right of human intervention creates in Article 22.

\subsection{Article 22(2) (c) - consent as an exception}

Under Article 15 of the DPD, the consent from the data subject did not qualify as an exception. $^{250}$ The condition for making use of this derogation is that the consent is given explicitly. This has by the Regulation been defined as:

'consent' of the data subject means any freely given, specific, informed and unambiguous indication of the data subject's wishes by which he or she, by a statement or by a clear affirmative action, signifies agreement to the processing of personal data relating to him or her; ${ }^{251}$

For the purpose of Article 22, the data subject must have been informed about the automated decision making and profiling ${ }^{252}$, in addition to giving a specific and unambiguously consent to this. The preamble provides an example of what is considered to be a specific and unambiguous:

"[t]his could include ticking a box when visiting an internet website, choosing technical settings for information society services or another statement or conduct which clearly indicates in this context the data subject's acceptance of the proposed processing of his or her personal data. Silence, pre-ticked boxes or inactivity should not therefore constitute consent."253

\footnotetext{
249 COM 2012/11, COD 2012/11 and Doc.15395/14

250 Section $6 \mathrm{~B}(2)$ (b) to the Irish Data Protection Act made an exception for the data subjects consent, making it the only country in Europe to do so. See Korff (2002) p. 112.

251 Article 4(11) GDPR

252 This follows also from Article 13(2) (f), 14(2) $\mathrm{g}$ and 15(1) h.

253 Preamble (32).
} 
It is possible to set up an opt-in solution on a website, so it will be relatively easy for websites to obtain consent. Given the relative strength between websites and users, it would not be difficult to put in place such solutions. ${ }^{254}$ This has also been commented by Borgesius, who writes that the proposal from the Commission "thus introduces yet another default rule that can be overridden with consent." ${ }^{, 255}$ However, the criterion freely given has been regulated more carefully in Article 7(4) to the GDPR:

When assessing whether consent is freely given, utmost account shall be taken of whether, inter alia, the performance of a contract, including the provision of a service, is conditional on consent to the processing of personal data that is not necessary for the performance of that contract.

Article 7 regulates the conditions for consent given as a legal ground for the processing of personal data, c.f. Article 6, and it is therefore not directly applicable to Article 22. Still, it must be presumed that the lawmakers meant for the same terms within a Regulation to be understood in the same way. Thus, Article 7(4) should bear some weight when interpreting the criterion of consent in Article 22. The problem of conditional offers (which creates take-itor-leave-it situations) is for that reason part of the assessment on whether the condition is freely given under Article 22. Article 7 does not prohibit conditional offers; it just states that one must take "utmost account" for it in the assessment of whether the consent is freely given.

As part of this assessment, Article 7(4) states that one should examine whether the conditional processing of personal data is actually "necessary" for the realization of the contract or service provided. Thus, if this element of the examination is to be copied under Article 22(2) (c), one should ask whether a conditional automated decision actually is necessary for the offered services. This assessment is, therefore, similar to the question of "necessity" as examined under the contractual exception.

It is difficult to draw the line for when automated decisions are necessary, and it should be left to courts to clarify. It can, however, be claimed that the interest the data subject has in the automated decision is a factor in the assessment. It is easier to argue that consent is freely given if the automated decision is in the interest of the data subject, such as in the situation of loan applications and insurance underwriting. It is, however, more difficult to imagine that consent is given freely for the purposes of price differentiation.

\footnotetext{
254 Koops (2014) pp. 251-252.

255 Borgesius (2015) p. 380.
} 
Article 22(2) c does not mention whether the consent can be withdrawn for future automated decision making. Consent in other parts of European data protection law, is however understood in this way. ${ }^{256}$ Article $22(2) \mathrm{c}$ should consequently be interpreted in the same manner. Nevertheless, the act of withdrawing consent will only have future effects and will not make previous automated decisions illegal. This is also the case for consent given as legal grounds for processing personal data under Article 7(3).

An isolated assessment of this new exception suggests that the Article 22(3) (c) widens the possibility of profiling and automated individual decisions. However, the consent exception does not apply in isolation, as the data controller still needs to put in place suitable measures to safeguard the data subject, including the right of human involvement under Article 22(3).

\subsection{Article 22(4) - the prohibition of decisions based on sensitive data}

The new prohibition in paragraph 4 of Article 22 reads as follows:

4. Decisions referred to in paragraph 2 shall not be based on special categories of personal data referred to in Article 9(1), unless point (a) or (g) of Article 9(2) apply and suitable measures to safeguard the data subject's rights and freedoms and legitimate interests are in place.

The paragraph prohibits decisions "referred to in paragraph 2" when they are based on special categories of data as regulated by Article 9(1). Paragraph 2 refers to the automated decisions in the first paragraph. The reason the prohibition refers to paragraph 2 and not paragraph 1, is presumably in order to stress that the prohibition takes precedence over the exceptions.

Article 9(1) gives a list of personal data considered to be special: racial and ethnic data, political opinions, religious and philosophical beliefs, trade union membership, health, sex life, sexual orientation, and genetic and biometric data for the purpose of uniquely identifying a natural person.

A study by researchers from the University of Cambridge shows how easy it is to make automated predictions containing sensitive data about people, solely based on their Facebook "likes." 257 The accuracy of their predictions varied, but it was high in detecting the ethnic ori-

\footnotetext{
256 Article 7(3).

257 Facebook has an integrated "Like" button to the content that is displayed in the personalized news feed. Michael Kosinski (2013).
} 
gins of the data subjects (95\%); their political affiliation (either Democrat or Republican $85 \%)$; whether they identified as a Christian or Muslim (82\%); the sexual orientation of the data subjects ( $88 \%$ for men and $75 \%$ for women); and the relationship status of the person as well as their use of alcohol, drugs, and cigarettes (between $65 \%$ and $73 \%$ ). ${ }^{258}$ Their lowest accurate prediction was whether the person's parents had separated before the users' turned twenty-one years old $(60 \%)$ :

"Although it is known that parental divorce does have long term effects on young adults' well-being, it is remarkable that this is detectable through their Facebook Likes. Individuals with parents who separated have a higher probability of liking statements preoccupied with relationships, such as "If I'm with you then I'm with you I don't want anybody else.",259

The application of the new prohibition can, therefore, seem to have a practical scope. The rationale is that decisions based on this data are more intrusive and present more harming profiling than the regular automation of decisions.

However, the new prohibition does not come without possibilities for derogation. There are two possible exceptions to the ban, namely explicit consent from the data subject for one or more specific purpose under Article 9(2) (a), or when such automated decisions are necessary for reasons of substantial public interest, and it has a basis in union or member state law under Article 9(2) (g). The exception of public interest and union or member state law will not be examined in this thesis, as there will be a variation between the Member States and since there probably have not been made such exceptions yet. ${ }^{260}$

Explicit consent in Article 9(2) (a) must be interpreted in the same manner as in Article 7, as accounted for in the previous subsection. The condition of suitable safeguards is also obligatory for derogations under Article 22(4), similar to the exceptions in the second paragraph. This will presumably be interpreted in the same manner as discussed in subsection 6.4.2 and will also include human intervention in the decision making. If this is "at least" required by the data controller in the ordinary decision, then it should also be a safeguard when the decision is based on sensitive data.

\footnotetext{
258 Michael Kosinski (2013) p. 5803

259 Michael Kosinski (2013) p. 5803

260 The GDPR will not take effect before $25^{\text {th }}$ May 2018 according to Article 99 of the GDPR.
} 


\subsection{The practical application of Article 22}

The overriding question in this subsection is whether the level of protection that Article 22 provides is higher for the citizen than under Article 15. The underlying question is if the right to demand human re-examination applies to more cases of automated decisions.

As concluded in subsection 6.1 above, the changes made to Article 22(1) are virtually insignificant. The provision is structured differently, as it includes "profiling" in the wording, but it requires similar interpretation and scope to Article 15 of the DPD. However, one might argue that the emphasis of the danger of profiling and discrimination, allow the provision to encompass less significant decisions.

The preamble also supports this, as the refusal of "online credit applications" and "erecruiting practices" are mentioned explicitly as automated decisions with significant effects. ${ }^{261}$ The preamble also suggests other measures that the decision maker should avoid in order to have a fair and transparent processing, such as decisions with discriminatory effects on the basis of racial and ethnic origins, political opinions, religion and other beliefs, health status, and sexual orientation. ${ }^{262}$ If the automated decision targets a child, it would also easily be considered significant. ${ }^{263}$

The focus on discriminatory decisions is an argument in favor of applying Article 22 to weblining, and Vermeulen concurs:

"It appears that the profiling that would result in price discrimination would be covered by the proposal, but the mere showing of a targeted advertisement probably might not."264

However, the biggest difference between Article 15 and Article 22 is not the scope of the right itself but the possibilities of derogations. Firstly, the new exception of explicit consent will encompass the automated decisions that have not already been derogated through a contract. Automated decisions with the possibility of discriminatory effects, such as weblining and online behavioral advertising, which could fall within the scope of Article 15 of the DPD, will easily qualify for exception through explicit consent. The prohibition provided by Article 22(4) also suffers from the fact that it can easily be derogated by obtaining explicit consent.

\footnotetext{
261 Preamble (71).

262 Ibid.

263 Preamble (38).

264 Vermeulen (2013) p. 12. This was in relation to the initial proposal from the Commission, but it had the same structure and mostly the same wording as the current Article 22.
} 
An example is an online newspaper that prompts the data subject for consent. As long as this becomes standard practice, like accepting terms and conditions today, then the new exception will de facto lower the level of protection for individuals. ${ }^{265}$ This is especially the case when considering the relative strength between most individuals and banks, insurance companies, and online service providers. However, the GDPR has tightened the assessment of what is a freely given consent and whether automated decisions are necessary for the purpose of entering into or performance of a contract. Both these requirements rest on how strict the term necessity should be interpreted under the Regulation.

The level of protection under the new Article will also to a large extent depend on what safeguards the data controller is obliged to put in place under Article 22(3). And here Article 22 offers a higher level of protection than the DPD, as the data subject always will have the right to demand manual re-examination of the decision. In conclusion, it is thus safe to assume that the level of protection will be higher under the GDPR than the DPD.

265 Koops (2014) p. 251-252 and Bygrave (2015a) p. 31-32. 


\section{$7 \quad$ Concluding remarks}

The concluding remarks will aim at tying the three main questions of the thesis together and give some comments regarding Article 22 of the GDPR in more general terms. This is not an attempt at assessing the law dogmatically, but an expression of my personal views, though it is based on the conclusions arrived at in this thesis.

The first main question in this thesis was under what conditions Article 15 applies. I believe that the provision today can be fulfilled by several automated services on the Internet. This is clearest for the cases of refusal of online bank loans, the rejection of a job application taken by e-recruiting software and the automated underwriting of insurance. Some types of weblining and OBA practices might also be encompassed by the Article, but it will probably require some discriminatory consequences.

This is also the conclusion for the applicability of section 25 of the Norwegian Act, which implements Article 15. This part of the thesis shows that even though the transposition of the Directives can be done very differently, EU and EEA law will still require a significant level of harmonization.

I believe that the lawmakers successfully understood how profiling and automated decision making would evolve. Yet, the lawmakers could not have anticipated the extent to which contracts would be used online, and therefore how practical the exception would become in Article 15(2). The contractual exception in Article 15(2) can be utilized for the examples of loan applications, e-recruiting practices, and the underwriting of insurance, but not for weblining and OBA practices. However, the decision maker needs to put in place safeguards such as facilitating the opinions of the data subject. This may remedy automated decisions that incorrectly result in discriminatory effects.

The reasons for the lack of case law regarding Article 15 must consequently be sought answered beyond the wording of the provision itself. The problems with enforcing the provision might stem from factors other than the design and framing of the legislation. It could for instance be argued that the average European citizen does not have enough information to challenge profiling activities. ${ }^{266}$

Article 22(1) of the GDPR will to a large extent comprise the same decisions as the DPD, but it will in total provide a higher level of protection than the current law. This is not because the

266 Colonna (2016) p. 170 
right under Article 22(1) has a wider scope than Article 15 but because the derogations under Article 22(2) are more limited compared to the current law.

The new exception for consent can at first seem as widening the possibility for derogation to a large extent. However, for the consent to be considered given freely, one must make a closer examination of the level of strength between the data subject and the decision maker. This exception can be proved hard to take advantage of, as much profiling done today is by socalled conditional consent (take-it-or-leave-it situations of different Internet services).

The contractual exception has also been tightened under Article 22. There is some legal uncertainty as to how strict "necessary" for entering into or performing a contract shall be interpreted. But if the interpretation of it follows the same tendency as with the assessment of freely given consent, it may be hard to derogate on the basis of this criterion.

In addition, the data subject will always have the right to human intervention under Article 22 (3), as opposed to Article 15. This means, in my opinion, that companies and governments will have no incentive for acquiring either a contract or consent from the data subject, as neither will actually work as a de facto exception to the provision. This is an unfortunate development of the right, as the automation of some important decision making could be beneficial for society, such as loan applications and the granting of credit in online shops.

The persons who will make use of their right under Article 22(3) will be the individuals who did not get the loan, the credit, or the insurance they wanted. Thus, the existence of the right to demand human involvement might have the effect of banks or insurance companies being more liberal in giving such services. A possible assessment these companies face is what it costs to take the risk of entering into an automated contract with persons of low creditworthiness. This risk could also negatively affect society as a whole. One can also argue that some decisions should be made by automated means alone. Take for example the financial crises of 2008, which has been attributed to "human action and inaction, not of Mother Nature or computer models gone haywire.",267

The case of e-recruiting is different from automated scoring techniques, as banks or insurance firms in principle can enter into a contract with an unlimited number of people. The purpose of e-recruiting is to save the cost of working through hundreds of applicants for a job posi-

267 The Financial Crisis Inquiry Report (2011)

<https://www.gpo.gov/fdsys/pkg/GPO-FCIC/pdf/GPO-FCIC.pdf> p. xvii. Last visited 18.05.2016. 
tion. $^{268}$ If every person who is turned down demands human involvement, it would possibly undermine the market for this type of technology.

However, it is important to have a provision such as Article 22 of the GDPR. The automation of different business sectors can give rise to decision making that should not be in the hands of an algorithm alone. This is particularly in the cases where the automation can lead to discriminatory decisions based on profiling, as can be the case with price differentiation and behavioral advertising. The exceptions for consent and contract have to some extent incorporated an assessment of proportionality. But the right of human involvement as a safeguard, gives the provision the design of a catch-all clause, which can disrupt the beneficial automation of industry without the possibility of a more risk-based approach to profiling and automated decision making. ${ }^{269}$

268 E.g when 300 people applied for two positions at the Norwegian grocery store Rema 1000. See Løkkebø (2011).

269 This view was also taken by the Justice Committee in the British House of Commons. See Vermeulen (2013) page 12 . 


\section{$8 \quad$ Bibliography ${ }^{270}$}

\subsection{Treaties}

TFEU OJ C 326. Consolidated version of the Treaty on the Functioning of the European Union.

TEU C $115 / 13$ Consolidated version of the Treaty of the European Union.

CETS 108 Convention for the Protection of Individuals with regard to Automatic Processing of Personal Data

EEA agreement OJ L 1 31.3.1994. Agreement on the European Economic Area.

\subsection{Legislation}

\subsubsection{EU legislation}

95/46/EC OJ L 281. Directive 95/46/EC of the European Parliament and of the Council of 24 October 1995 on the protection of individuals with regard to the processing of personal data and on the free movement of such data.

2016/679/EU OJ L 119. Regulation of the European Parliament and the Council of 27 April 2016 on the protection of natural persons with regard to the processing of personal data and on the free movement of such data, and repealing Directive 95/46/EC (General Data Protection Regulation)

2016/680/EU OJ L 119 Directive of the European Parliament and of the Council of 27 April 2016 on the protection of natural persons with regard to the processing of personal data by competent authorities for the purposes of the prevention, investigation, detection or prosecution of criminal offences or the execution of criminal penalties, and on the free movement of such data, and repealing Council Framework Decision 2008/977/JHA.

93//13/EEC OJ L 095. Council Directive of 5 April 1993 on unfair terms in consumer contracts.

270 The GDPR is by the submission of this thesis relatively new. The references to the legislative documents from the Commission, the Parliament and the Council is therefore partly based on leaked documents. I try remedy this by linking the relevant documents. 


\subsubsection{Domestic legislation}

$\begin{array}{ll}1978 & \text { French Data Protection Act } \\ & \text { <https://www.cnil.fr/sites/default/files/typo/document/Act78- } \\ & \underline{\text { 17VA.pdf> last accessed 25.05.2016. }} \\ & \text { UK Data protection Act. } \\ & \text { <http://www.legislation.gov.uk/ukpga/1998/29/contents> Last ac- } \\ & \text { cessed 25.05.2016. } \\ & \text { (Norwegian Act) Lov 14 april } 2000 \mathrm{nr} .31 \text { om behandling av per- } \\ & \text { sonopplysninger (personopplysningsloven). } \\ & \text { <https://www.datatilsynet.no/English/Regulations/Personal-Data-Act- } \\ & \text { > last accessed 25.05.2016. } \\ & \text { German Data Protection Act <http://www.gesetze-im- } \\ & \text { internet.de/englisch_bdsg/> last accessed 25.05.2016. }\end{array}$

\subsection{Case law}

\subsubsection{The European Court of Justice}

Case C-283/81 Srl CILFIT and Lanificio di Gavardo SpA v.

EU:C:1982:335

Ministry of Health

Case C-152/84 Marshall v. Southampton and South-West

EU:C:1986:84

Hamsphire Area Health Authority

Case C-268/99 Jany and Others v. Staatssecretaris van Justitie.

EU:C:2001:616

Case C-465/00 Rechnungshof v. Österreichischer Rundfunk

EU:C:2003:294

Case C-101/01 Lindqvist

EU:C:2003:596

Case C-524/06 Huber v. Bundesrepublik Deutschland

EU:C:2008:724

Joined Cases C-402/07 and C-432/07

EU:C:2009:716

Joined cases C-468/10 and C-469/10 ASNEF \& FECEMD v.

EU:C:2011:777

Administración del Estado

Case C-473/12 IPI v. Geoffrey Engelbert and Others

EU:C:2013:715

\subsubsection{The Norwegian Supreme Court}

Rt-2000-1811 (Finanger I)

Rt-2002-391 (God Morgon)

Rt-2004-122 
Rt-2006-1473

8.3.3 Others

PVN-2014-1

The Norwegian Data Protection Tribunal. Skan-

Kontroll.

\subsection{Reports and other documents}

\subsubsection{The European Commission}

COM(90) 314 final - SYN 287

90/C 277/03. Proposal for a Council Directive concerning the protection of individuals in relation to the processing of personal data. <http://eur-lex.europa.eu/legalcon-

tent/EN/TXT/PDF/?uri=CELEX:51990PC0314(01)\&from $\underline{=\mathrm{EN}}>$ Last accessed 25.05.2016

COM(92) 422 final - SYN 287 92/C 311/04. Amended proposal for a Council Directive on the protection of individuals with regard to the processing of personal data and the free movement of such data. <http://eur-lex.europa.eu/legal-

content/EN/TXT/PDF/?uri=OJ:JOC_1992_311_R_0030_01\& from $=\mathrm{EN}>$ Last accessed 25.05.2016.

COM $314(1990)$

(Explanatory memorandum to first proposal). Commission Communication on the protection of individuals in relation to the processing of personal data in the Community and Information Security. 〈http://aei.pitt.edu/3768/1/3768.pdf> Last accessed 25.05.2016.

COM 442 (1992)

(Explanatory memorandum to the amended proposal). <http://aei.pitt.edu/10375/1/10375.pdf > Last accessed 25.05.2016.

SEC(2012) 72 Final

Impact Assessment <http://ec.europa.eu/justice/dataprotection/document/review2012/sec_2012_72_en.pdf $>$ Last accessed 25.05.2016.

SEC(2012) 73 Final Executive summary of Impact summary. <http://ec.europa.eu/justice/dataprotection/document/review2012/sec_2012_73_en.pdf > last accessed 25.05.2016. 

pean Parliament and of the Council on the protection of individuals with regard to the processing of personal data and on the free movement of such data (General Data Protection Regulation). <http://eur-lex.europa.eu/legalcontent/EN/TXT/?uri=COM:2012:0011:FIN>

\subsubsection{The European Parliament}

92/C $67 / 03$

95/C 166/04

91/C $159 / 14$

Albrect, Jan Philipp

2012/C 229/17
(Amendments of Parliament at first reading). OJ C 94 13.4.92.

Minutes of proceedings of the sitting of Wednesday, 11 March 1992.

$<$ http://eur-lex.europa.eu/legal-

con-

tent/EN/TXT/PDF/?uri=OJ:JOC_1992_094_R_0063_01\&from=EN>

Last accessed 25.05.2016

(Amendments of Parliament at second reading). OJ C 155 3.7.95

Minutes of proceedings of the sitting of Thursday, 15 June 1995.

$<$ http://eur-lex.europa.eu/legal-

con-

tent/EN/TXT/PDF/?uri=OJ:JOC_1995_166_R_0077_01\&from=EN>

Last accessed 25.05.2016.

Opinion on: - the proposal for a Council Directive concerning the protection of individuals in relation to the processing of personal data, - the proposal for a Council Directive concerning the protection of personal data and privacy in the context of public digital telecommunications networks, in particular the integrated services digital network (ISDN) and public digital mobile networks, and - the proposal for a Council Decision in the field of information security. <http://eurlex.europa.eu/legalcontent/EN/TXT/PDF/?uri=CELEX:51991IE0570\&from=EN> last accessed 25.05.2016.

TA/2014/212/P7.

$<$ http://www.europarl.europa.eu/sides/getDoc.do?pubRef=//EP//TEXT\%20TA\%20P7-TA-20140212\%200\%20DOC\%20XML\%20V0//en> last accessed 25.05.2016. OJ C 229 p.90 <http://eur-lex.europa.eu/legal- 
content/EN/TXT/PDF/?uri=CELEX:52012AE1303\&from=EN> last accessed 25.05.2016.

\subsubsection{The European Council}

95/C 93/01 Common position (EC) No 1/95 on 20 February 1995 adopted by the Council acting in accordance with the procedure referred to in Article $189 \mathrm{~b}$ of the Treaty establishing the European Community, with a view to adopting a Council and European Parliament Directive on the protection of individuals with regard to the processing of personal data and on the free movement of such data.

Doc. The Council Position. <http://data.consilium.europa.eu/doc/document/ST15395/14 $\quad \underline{15395-2014-I N I T / e n / p d f>}$ last accessed 25.05.2016.

\subsubsection{The Council of Europe}

CM/Rec(2010)13 Council of Europe (2010). The protection of individuals with regard to automatic processing of personal data in the context of profiling. <http://www.coe.int/t/dghl/standardsetting/cdcj/CDCJ\%20Recomm endations/CMRec(2010)13E_Profiling.pdf> Last accessed 15.05.2016.

Dinant, Jean-Marc Application of Convention 108 to the profiling mechanism. 2008.

Lazaro, Christophe

Poullet, Yves

Lefever, Nathalie

Rouvroy, Antionette

\subsubsection{Working Party 29}

WP 171 Opinion 2/2010 on online behavioural advertising. <http://ec.europa.eu/justice/policies/privacy/docs/wpdocs/2010/wp171_en.pdf> Last accessed 25.05.2016

WP216 Opinion 05/2014 on Anonymisation Techniques. <http://www.cnpd.public.lu/fr/publications/groupe-art29/wp216_en.pdf> Last accessed 25.05.2016

WP 136 Opinion 4/2007 on the concept of personal data. 〈http://ec.europa.eu/justice/policies/privacy/docs/wpdocs/2007/wp136_en.pdf> last accessed 25.05.2016. 


\subsubsection{Norway}

NOU 1997:19

Ot.prp.nr.92 (1998-1999)

Innst.O.nr.51 (1999-2000)

NOU 2009:1
Et bedre personvern

Om lov om behandlinger av personopplysninger (personopplysningsloven).

Instilling fra justiskomiteen om lov om behandling av personopplysninger (personopplysningsloven).

Individ og integritet - Personvern i det digital samfunnet.

\subsubsection{Data Protection Authorities}

VEJ nr 126 (2000)

Opinion 35 (2012)

Datatilsynet.

\subsubsection{Others}

Batty, Mike

Kroll, Alice

Deloitte Consulting Group

Beales, Howard

Leon, Pedro Giovanni

Cranshaw, Justin

Cranor, Lorrie Faith

Graves, Jim

Hastak, Manoj
Danish Data Protection Authority (2000). Vejledning om registreredes rettigheder efter reglerne i kapitel 8-10 I lov om behandling af personoplysninger.

$<$ https://www.retsinformation.dk/Forms/R0710.aspx?id=852> Last accessed 15.05.2016.

Belgian Data Protection Authority (2012).

$<$ https://www.privacycommission.be/sites/privacycommission/files/d ocuments/opinion_35_2012_0.pdf> Last accessed 15.05.2016.

The Big Data Race (2015).

$<$ https://www.datatilsynet.no/globalassets/global/04_analyser_utredni nger/2015/engelsk-kommersialisering-november-2015.pdf> Last accessed 15.05.2016.

Automated Life Underwriting (2009). <https://www.soa.org/Files/Research/Projects/research-life-autounderwriting.pdf.> Last accessed 25.05.2016.

The Value of Behavioral Advertising (2010). 〈http://www.networkadvertising.org/pdfs/Beales_NAI_Study.pdf〉 Last accessed 25.05.2016.

What Do Online Behavioral Advertising Privacy Disclosures Communicate to Users? 2012.

<https://www.cylab.cmu.edu/files/pdfs/tech_reports/CMUCyLab1200 8.pdf $>$ last accessed 25.05.2016. 
Ur, Blase

$\mathrm{Xu}, \mathrm{Guzi}$

Kosinski, Michael

Stillwell, David

Graepel, Thore

Mikians, Jakub

Gyarmati, Lázló

Erramilli, Vijay

Laoutaris, Nikolaos

Mikians, Jakub

Gyarmati, Lázló

Erramilli, Vijay

Laoutaris, Nikolaos

Papaodyssefs, Fotios

Iordanou, Costas

Blackburn, Jeremy

Laoutaris, Nikolaos

Stone-Gross, Brett,

Stevens, Ryan

Kemmerer, Richard

Kruegel, Christopher

Vigna, Giovanni

Thomas, L. C.,

Edelman, David B.

Crook, Jonathan N.

Yan, Weizhong

Bonissone, Perio P.
Private traits and attributes are predictable from digital records of human behavior. PNAS, 2013. Volume 110 issue 15.

$<$ http://www.pnas.org/content/110/15/5802.full > Last accessed 25.05.2016.

Detecting price and search discrimination on the Internet. 2012. <http://conferences.sigcomm.org/hotnets/2012/papers/hotnets12final94.pdf $>$ last accessed 25.05.2016.

Crowd-assisted Search for Price Discrimination in E-commerce: First results. 2013. < http://conferences.sigcomm.org/conext/2013/program/p1.pdf $>$ last accessed 25.05.2016.

Web Identity Translator. Behavioral Advertising and Identity Privacy with WIT. 2015.

<http://conferences.sigcomm.org/hotnets/2015/papers/papodyssefs.pd f $>$ last accessed 25.05.2016.

Understanding Fraudulent Activities in Online ad Exchanges. 2011. <http://conferences.sigcomm.org/imc/2011/docs/p279.pdf > last accessed 25.05.2016.

Credit scoring and its applications, Credit Scoring and Its Application. Society for Industrial and Applied Mathematics. 2002.

Designing a Neural Network Decision System for Automated Insurance Underwriting. International Joint Conference on Neural Networks. 2006.

<http://ieeexplore.ieee.org/xpls/abs_all.jsp?arnumber=1716371\&tag= $1>$ last accessed 25.05.2016.

\subsection{Legal literature}

\subsubsection{Books}

Anrig, Bernhard

Browne, Will

The Role of Algorithms in Profiling, In: Profiling the European Citizen edited by Mireille Hildebrandt and Serge Gut- 
Gasson, Mark

Arnesen, Finn

Stenvik, Are

Bing, Jon

Blume, Peter

Blume, Peter

Boe, Erik

Boe, Erik

Borgesius, Frederik J. Zuiderveen

Bosco, Francesca

Creemers, Niklas

Ferraris, Valeria

Guagning, Daniel

Koops, Bert-Jaap

Bosco, Francesca

Creemers, Niklas

Ferraris, Valeria

Guagnin, Daniel

Koops, Bert Jaap

Vermeersch, Elise

Büllesbach, Alfred

Bygrave, Lee A.

Bygrave, Lee A.

Bygrave, Lee A. wirth. 2010, pp. 65-87.

Internasjonalisering og juridisk metode: særlig om EØSrettens betydning i norsk rett. $2^{\text {nd }}$ edition, 2015.

Rettslige kommunikasjonsprosesser: bidrag til en generell teori. 1982.

Data Beskyttelses Ret. 2008, $3^{\text {rd }}$ edition.

Behandling av Persondata. En kritisk kommentar. 2003.

Innføring i juss: en juridisk tenkning og rettskildelære. 3rd edition. 2010.

Rettskildelære under debatt. 2012.

Improving privacy protection in the area of behavioural advertising. 2015.

Profiling Technologies and Fundamental Rights and Values: Regulatory challanges and Perspectives from European Data Protection Authorities, In: Reforming European Data Protection Law, edited by Ronald Leenes, Serge Gutwirth and Paul De Hert, 2014, pp. 3-35.

Profiling Technologies and Fundamental Rights. An introduction, In: Profiling Technologies in Practice. Edited by Niklas Creemers, Daniel Guagnin, Bert Jaap Koops. 2015, pp. 5-21.

Concise European IT Law. $2^{\text {nd }}$ edition, 2010.

Data protection law: approaching its rationale, logic and limits. 2002.

Data privacy law: an international perspective, 2014.

Internet Governance by Contract, 2015a. 
Colonna, Liane

Craig, Paul

De Búrca, Gráinne

Custers, H. M.

Duhigg, Charles

Eckhoff, Torstein

Helgesen, Jan E.

Eide, Erling

Stavang, Endre

Fredriksen, Halvard Haukland

Mathisen, Gjermund

Gutwirth, Serge

De Hert, Paul

Hildebrandt, Mireille

Johansen, Michal Wiik

Skullerud, Åste Marie Bergseng

Kaspersen, Knut B.

Korff, Douwe

Kvam, Bjarne

Lilleholt, Kåre
Legal Implications of Data Mining: Assessing the European Union's Data Protection Principles in Light of the United States Government's National Intelligence Data Mining Practices. 2016.

EU Law : text, cases and materials. $5^{\text {th }}$ edition, 2011.

The Power of Knowledge: Ethical, Legal and Technological Aspects of Data Mining and Group Profiling in Epidemoilogy. 2004.

The Power of habit: why we do what we do in life and business. 2012.

Rettskildelære. $5^{\text {th }}$ edition. Edited av Jan E. Helgesen. 2001.

Rettsøkonomi. 2008.

EØS-rett. 2012.

Regulating Profiling in a Democratic Constitutional State. In: Profiling the European Citizen, edited by Mireille Hildebrandt and Serge Gutwirth. 2010, pp. 271-303.

Defining Profiling: A New Type of Knowledge? In: Profiling the European Citizen, edited by Mireille Hildebrandt and Serge Gutwirth. 2010, pp. 17-47.

Personopplysningsloven: kommentarutgave 2001.

Data protection laws in the European Union. 2005.

Politiets persondatarett: en studie av hjemmels- og formålskrav ved politiets utlevering av personopplysninger til utlandet. 2014b.

Kontraktsrett og Obligasjonsrett, In: Knophs oversikt over Norges Rett, edited by Kåre Lilleholt. 2014, $14^{\text {th }}$ edition, pp.210-277. 
Öman, Sören

Lindblom, Hans-Olof

Prechal, Sacha

Schartum, Dag Wiese

Bygrave, Lee A.

Schermer, Bart

Schreurs, Wim,

Hildebrandt, Mireille

Kindt, Els

Vanfleteren, Michaël

Sejersted, Fredrik

Udsen, Henrik

Young, Alasdair R.

\subsubsection{Articles}

Borońska-Hryniewiecka, Karolina

Bygrave, Lee A.

Bygrave, Lee A.
Personuppgiftslagen: en kommentar. 2011

Directives in EC Law. 2005.

Personvern i informasjonssamfunnet: en innføring i vern av personopplysninger. 2011.

Risks of Profiling and the Limits of Data Protection Law, In: Discrimination and Privacy in the Information Society. Edited by Bart Custers, Toon Calders, Bart Schermer, Tal Zarsky. 2013, pp. 137-155.

Cogitas, Ergo Sum. The Role of Data Protection Law and Non-discrimination law in Group Profiling in the Private Sector. In: Profiling the European Citizen, edited by Mireille Hildebrandt and Serge Gutwirth. 2008, pp. 241-271.

Gjennomføringen av EØS-retten i norsk rett. In EØS-rett, edited by Finn Arnesen Fredrik Sejersted, Ole-Andras Rognstad, Sten Foyn og Olav Kolstad. 2011 pp. 195-219.

De informationsretlige grundsætninger: studier i informationsretten. 2009.

The European Policy Process in Comparative Perspective. In Policy-Making in the European Union, edited by Helen Wallace, Mark A. Pollack and Alasdair R. Young. 2015, pp. 45-68.

The Black Box of European Legislation: The Motivation (or Lack of It) behind Transparency in EU Policymaking. Policy Paper from the Polish Institute of International Affairs. 2015.

Automated profiling - Mining the Machine: Article 15 of the EC data protection directive and automated profiling. Computer Law and Security Report 17, 2001, p. 17-24.

Information concepts in law: generic dreams and definitional daylight. Oxford Journal of Legal Studies 35. 2015b, p. 91-120. 
Faliagka, Evanthia

Tsakalidis, Athanasios

Tzimas, Giannis

King, Nancy J.

Koops, B. J.

Kvam, Bjarne

Vermeulen, Mathias
An Integrated E-Recruitment System for Automated Personality Mining and Applicant Ranking. Internet Research Volume 22, issue 5 p. 551-568. 2012.

When Mobile Phones are RFID-Equipped - Finding E.U.-U.S. Solution to Protect Consumer Privacy and Facilitate Mobile Commerce. Michigan Telecommunications and Technology Law Review Volume 15 issue 12008.

The trouble with European data protection law. International Data Privacy law. Volume 4 issue 4. 2014. Er personopplysningsloven i strid med EØS-retten? EU-domstolens krav til harmonisering. Lov og Data. 2014a.

Regulating profiling in the European Data Protection Regulation. An interim insight into the drafting of Article 20. 2013. <http://emsoc.be/wpcontent/uploads/2013/11/D3.2.2-Vermeulen-Emsocdeliverable-profiling-Formatted1.pdf $>$ last accessed 25.05.2016.

\subsubsection{Conference papers}

Colonna, Liane Mo' Data, Mo' Problems? Personal Data Mining and the Challenge to the Data Minimization Principle. Conference proceedings of Big Data and Privacy: Making Ends Meet hosted by Stanford Law School and The Center for Internet and Society, 2013. <https://fpf.org/wpcontent/uploads/Colonna-Mo-Data-Mo-Problems.pdf $>$ Last accessed 25.05.2016.

Savin, Andrej Profiling and Automated Decision Making in the Present and New EU Data Protection Frameworks. 7th International Conference Computers, Privacy \& Data Protection. 2014. <http://openarchive.cbs.dk/handle/10398/8914> last accessed 25.05.2016. 


\subsubsection{Others}

Fredriksen, Halvard Haukland

Hildebrandt, Mireille

Korff, Douwe

Korff, Douwe

Simitis, Spiros

Dammann, Ulrich

Körner, Marita
EU/EØS-rett i norske domstoler. Rapport 3 til Europautredningen. 2011.

The Rule of Law in Cyberspace. 2010.

<http://works.bepress.com/mireille_hildebrandt/48/> last accessed 25.05.2016.

EC Study on Implementation of Data Protection Directive 95/46/EC. 2002.

Comments on Selected Topics in the Draft EU Data Protection Regulation. 2012.

$<$ http://papers.ssrn.com/sol3/papers.cfm?abstract_id=215 $\underline{0145}>$ Last accessed 25.05.2016

Data Protection in the European Community: The Statutory Provisions (loose-leaf). 1992.

\subsection{News articles and web pages}

Braseth, Sofie (2016)
Dagbladet (2016). Dating-appen Tinder rangerer deg i hemmelighet.

<http://www.dagbladet.no/2016/01/16/kultur/tinder/app/sjek king/dating/42776723/> Last accessed 15.05.2016

Credit \& Management Sys- Rules Based Credit Scoring Methodology. tems (1999)

Davenport, Thomas $\mathrm{H}$.

Harris, Jeanne G. (2005)

Grundberg, Sven

Hansegard, Jens (2014)

Gustafsson, Katarina

Magnussion, Niklas (2014) <https://www.crfonline.org/orc/cro/cro-15-1.html>

Last accessed 20.04.2016.

MIT Sloan Review (2005). Automated decision making comes of age.

$<$ http://sloanreview.mit.edu/article/automated-decisionmaking-comes-of-age/> Last accessed 12.05.2016

Wall Street Journal (2014). Sweden's Klarna: With U.S. Launch, It's All about Online Payment 'Friction'.

<http://blogs.wsj.com/digits/2014/09/19/swedens-klarnawith-u-s-launch-its-all-about-online-payment-friction/> Last accessed 25.05.2016

Bloomberg Technology (2014). Risk Algorithm Paves

Global Expansion for Klarna Payment Systems 
<http://www.bloomberg.com/news/articles/2014-02-02/riskalgorithm-paves-global-expansion-for-klarna-payment$\underline{\text { system }}>$ Last accessed 15.05.2016.

LobbyPlag (2013)

Løkkebø, Lars (2011)

Mattioli, Dana (2012)

Narayanan, Arvind (2013).

Oxford Dictionaries (2016)

Oxford Dictionaries (2016)

Oxford Dictionaries (2016)

Stepanek, Marcia (2000)
LobbyPlag (2013). "LobbyPlag” brings light to the EU Data Protection jungle. Online projects evaluates more than 3,100 amendments. <http://www.europe-vfacebook.org/LP_en.pdf $>$ Last accessed 16.05.2016.

Telemarksavisa (2011). 300 søkte på Rema 100 jobb. <http://www.ta.no/jobb/300-sokte-pa-rema-jobb/s/1-111$\underline{5504736}>$ Last accessed 25.05.2016

Wall Street Journal (2012). On Orbitz, Mac Users Steered to Pricier Hotels.

<http://www.wsj.com/articles/SB100014240527023044586 $\underline{04577488822667325882>}$ Last accessed 13.04.2016

33 Bits of Entropy (2013). Online price discrimination: Conspicuous by its absence.

< https://33bits.org/2013/01/08/online-price-discriminationconspicuous-by-its-absence/> Last accessed 25.02.2016

Click rate.

<http://www.oxforddictionaries.com/definition/english/click -rate?q=click+rate>

Last accessed 12.05.2016

Data.

<http://www.oxforddictionaries.com/definition/english/data

$>$ Last accessed 12.05.2016.

Credit score.

<http://www.oxforddictionaries.com/definition/english/credi

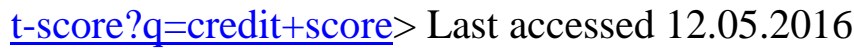

Bloomberg Businessweek (2000) Weblining. <http://www.businessweek.com/2000/00_14/b3675027.htm. $>$ Last accessed 25.05.2016.

Swayy, Shayna Hookin (2014) Wired (2014). The Internet of Me: Creating a Personlized 
Web Experience.

$<$ http://www.wired.com/insights/2014/11/the-internet-ofme/> Last accessed 25.05.2016.

Vogt, Yngve (2015)

Forskningsmagasinet Apollon (2015). Her er likhetene mellom kreft og skattejuks.

<http://www.apollon.uio.no/artikler/2015/3_datamengder_st atistikk.html> Last accessed 13.05.2016

Wilson, Christo (2014)

Washington Post (2014). If you use a Mac or an Android, ecommerce sites may be charging you more.

$<$ https://www.washingtonpost.com/posteverything/wp/2014/ 11/03/if-you-use-a-mac-or-an-android-e-commerce-sitesmay-be-charging-you-more/> Last accessed 13.04.2016 